\title{
Why Go to Court? Bargaining Failure under the Shadow of Trial with Complete Information*
}

\author{
Michael McBride \\ Department of Economics \\ University of California, Irvine \\ Pi-Han Tsai ${ }^{\dagger}$ \\ Stergios Skaperdas \\ Department of Economics \\ University of California, Irvine \\ Department of Economics, \\ University of California, Irvine
}

This version: April 2014

\begin{abstract}
Why do legal disputes ever go to trial? Prior research emphasizes the role of mistakes, irrationalities, or asymmetric information because rational litigants with complete or symmetric information should choose pre-trial settlements over the costs and risks of trial. Using a dynamic incomplete-contracting framework, we provide an overlooked rationale for going to court. Even though risky and costly, going to court can be both rational and socially efficient when a court decision enhances property rights and deters future costly litigation. Experimental evidence supports these predictions. Our findings provide new insights into the incidence of litigation and trial.
\end{abstract}

JEL Classifications: C72, K11, K41.

Keywords: litigation, court, conflict, contests.

\footnotetext{
${ }^{*}$ We thank the Center for the Study of Democracy at UC Irvine for financial support and the Experimental Social Science Laboratory for use of their facilities. McBride acknowledges financial support from Army Research Office Award No. \#W911NF-11-1-0332 and Air Force Office of Scientific Research Award No. FA9550-10-1-0569.

${ }^{\dagger}$ Corresponding author; Social Science Plaza A 3151, University of California, Irvine, CA 92607 USA; email address: pihant@uci.edu; 1-571-309-6962
} 


\section{Introduction}

Why do legal disputes ever go to trial? Early research predicted that rational litigants with complete information would avoid the costs and risks of trial by settling out of court (Landes 1971; Gould 1973; Posner 1973; Mnookin and Kornhauser 1979; Shavell 1982). It follows that "A trial is a failure" (Gross and Syverud 1991), and these and other papers have sought for alternative explanations. For example, trial could result from mistakes in strategy (Cooter et al. 1982), from structural features of the litigation setting such as agency problems between litigant and lawyer (Bibas 2004), or from irrationalities such as framing or self-serving biases (Bibas 2004). Yet, the explanation that has received the most attention is that the trial results when litigants have different information. Parties may be asymmetrically informed about the likelihood of winning a trial (Bebchuk 1984; Reinganum and Wilde 1986), one party may be overly optimistic about the strength of its case (Priest and Klein 1984), and more (see Spier 2007). Many of these explanations are grounded in game theoretic models of bargaining (Kennan and Wilson 1993).

The basic logic of our argument is as follows. Litigants must expend costly resources preparing legal cases in property rights disputes. ${ }^{1}$ As in the incompletecontracting literature (e.g., Grossman and Hart 1986; Hart and Moore 1990), agents can make short-term contracts (that is, settle out of court) but not long-term contracts. $^{2}$ Going to trial has additional costs and is risky because the court's ruling is not known. However, by going to trial now, the litigant may deter future litigation and settlement, and their associated high costs. This is true even when the direction of the court's ruling is symmetrically not known by the litigants or when actors have complete information about the relative merits of their cases. In short, asymmetric information is not necessary for a trial to occur.

Three particular features of litigation and court procedures that affect pre-trial

\footnotetext{
${ }^{1}$ This assumption has been made in other studies. For example, Wärneryd (2000) shows the relevance of this assumption for understanding the incentives to delegate in legal contests.

${ }^{2}$ The impossibility of long-term contracts should not be taken literally but, rather, what our approach illuminates are conditions under which private contracts are more incomplete than the settlements that may come from a court decision. Reasons for the usual incompleteness of contracts are discussed in Shavell (1998, p.438).
} 
bargaining are central to our argument. First, adversaries must expend costly resources, such as hiring lawyers and engaging in pretrial discovery, in order to make a claim in a dispute, regardless of whether the parties expect to go to court or settle. Second, trials are risky; even after pre-trial preparation, the outcome of the conflict depends on factors outside of the litigants' control that are hard to predict. This risk may be assessed asymmetrically by the litigants, as is assumed in much of the previous literature, but such is not necessary as we show here. Third, the winner of a trial enhances her position relative to her adversary not just today but also in the future because the trial verdict becomes the "law of the case" and the burden of proof shifts to the side that has lost. That is, a court decision enhances the property rights of the winner. ${ }^{3}$ The first two features are widely recognized as relevant for pre-trial settlements (e.g., Gould 1973; Lanjouw and Lerner 1998; Farmer and Pecorino 1999; Hirshleifer and Osborne 2001).

Previous research has acknowledged that this third feature matters, but how its crucial role in causing trial even with complete information has not been systematically articulated. For example, Cooter et al. (1982) acknowledge that this dynamic may affect the incidence of trial but do not develop the logic; Che and Yi (1993) examine how establishing a precedent affects the willingness of a defendant to settle out of court when facing multiple plaintiffs, yet they also assume asymmetric information; and Robson and Skaperdas (2008) model a similar two-period setting but address other questions and neither elaborate on nor test the robustness of its significance.

We first present the simplest model that illustrates the logic. When the stream of profits (i.e., the dispute horizon) is long enough, then there is no feasible outof-court settlement that is better than the expected payoff of trial. The level of property rights security also matters. We consider property rights as imperfect in the sense that a court decision does not go with certainty to the presumed holder of a property right, and property rights are considered better defined and more secure the larger is the probability of winning in court for the presumed holder. We find

\footnotetext{
${ }^{3} \mathrm{~A}$ related point that enhances our argument, made by Buchanan (1989) is that, in the absence of a challenge in court, property rights can weaken and "atrophy." In some civil law systems, for example, the concept of usucapio might allow even a long-term renter, not just a squatter, to acquire title over a real asset.
} 
that the better property rights are defined, the higher is the likelihood of settling out of court. Variations of the model - allowing for endogenous litigation costs and allowing litigants to have different dispute horizons - demonstrate the generality of this argument.

We next present results from a laboratory experiment in which we control both the degree of property rights security and the litigation horizon. Consistent with the theory, we find that subjects are more likely to choose trial when the litigation horizon is longer and when property rights are less secure. However, not all behavior conforms to the theory, and we show how the clarity in which information is conveyed to the subjects can influence their litigation decisions.

Our findings contribute to the literature on pre-trial settlement briefly reviewed above. We provide theory and experimental evidence of how the incidence of trials in complete information settings depends on both the profit horizon and the level of property rights security. We also show that trials can be efficient by preventing costly litigation in the future. That trials can be desirable has been noted before (e.g., Shavell 1982; Fiss 1984), albeit for different reasons. Whereas prior researchers have emphasized that errors in judgement may lead to too many trials (e.g., Gross and Syverud 1991), we also find that errors in judgment may also lead to too few trials in settings with moderate or insecure property rights. Additionally, we provide new evidence that the incidence of errors in the settle-or-trial decision depends on the manner in which dispute-relevant information is presented to litigants, a finding that has relevance to legal practitioners. These insights are discussed in greater detail at the end of the paper.

We also note that the laboratory proves to be a practical, even if imperfect, setting in which to test our theory. It is widely accepted that the cases that reach trial are not a random sample of all cases (e.g., Priest and Klein 1984; Lanjouw and Lerner 1998; Lederman 1999), yet without data on all cases it is difficult to identify empirically why some cases reach trial and others do not. Moreover, it is impractical to randomly assign profit horizons and property rights to real-world litigants. In the laboratory, however, we can assign subjects into litigant roles and easily control the level of property rights security and the dispute horizon. A few experimental studies 
on pre-trial bargaining take advantage of some of these features (e.g., Stanley and Coursey 1990; Loewenstein et al. 1993; Birkeland 2013). Hewitt (2012) is the only prior experimental study of which we are aware that varies both property rights and the stakes, but his experiment is tailored to cross-industry licensing whereas ours focuses on generic property rights disputes.

Finally, we note that economists and political scientists have shown how a dynamic similar to our third feature matters in violent conflict settings (e.g., Garfinkel and Skaperdas 2000; Bester and Konrad 2004; Powell 2006). The papers most closely related to our are McBride and Skaperdas (forthcoming) and Smith et al (2014). The former presents a basic model of war that reveals these insights and conducts a laboratory experiment to explore human behavior in this conflict setting. The later generalizes and experimentally tests the same basic model to a setting where the costs of war increase in the arming expenditures. Our paper differs by directly addressing the litigation setting and by controlling for different levels of property rights security.

\section{An Illustrative Model: Settlement vs. Going to Court}

\subsection{The Model}

Consider two litigants (or parties), $\mathrm{A}$ and B, who are in dispute over an asset that yields a return $R>0$ in each period $t=1,2, \ldots$ An example of such an asset would be land with title that is contested by two parties. In each period, each party can contest the asset by paying a "litigation fee" $L>0$. If both parties contest the asset, then they could bargain and settle on a disposition of the asset for that period or they could contest it in court, whereby both would have to pay a "court fee" $C>0$. For settlement to occur, both parties would have to agree, whereas just one party could force a trial in court. If only one of the parties pays the litigation fee, then that party enjoys the return of the asset for that period, and the other party receives no return. If neither party pays the litigation fee, then neither receives a return on the asset. We suppose that both parties discount the future by the constant discount factor $\delta \in(0,1)$. 
A court decision in any particular period awards the asset to one party not just for this period but for all subsequent periods. That is, a court decision makes the title of the asset perfectly secure via a perfect form of legal precedence. ${ }^{4}$ Let party $A$ 's probability of winning in court be $p$ and party $B$ 's probability of winning be $1-p$. Without loss of generality suppose $p \geq 1 / 2$. Party $A$ could be considered to have a temporary insecure title to the asset or "insecure property right," and $p$ could be considered the court's ability to discriminate in favor of the right party, with a $p$ closer to 1 signifying a greater ability of the court to discriminate in favor of the right party.

We have here assumed that the return on the asset is forgone if neither party prepares. An alternative, perhaps more realistic to some litigation settings, is to suppose that the favored party (A) receives the return by default if no challenge is offered, and that the favored party first observes the challenger's preparation decision before deciding to prepare. We consider these possibilities in the next section and see that our main logic still applies. But for now our current set-up enforces symmetry in all dimensions except for the likelihood of winning a trial. We can then be sure that our results do not hinge on some other form of asymmetry, such as default winner status.

\subsection{The Settle or Go-to-court Decision}

Suppose a period in which both parties have paid the litigation fee and face the choice between settlement and going to court. If they were to go to court, then their continuation payoffs would be as follows:

$$
\begin{aligned}
V_{A}^{c} & =p\left(R+\delta R+\delta^{2} R+\cdots\right)-C=p \frac{R}{1-\delta}-C, \\
V_{B}^{c} & =(1-p)\left(R+\delta R+\delta^{2} R+\cdots\right)-C=(1-p) \frac{R}{1-\delta}-C .
\end{aligned}
$$

Because each party has to pay the cost $C$ to go to court, there is an incentive to settle and divide the returns of the asset, possibly in accordance with the winning

\footnotetext{
${ }^{4}$ This assumption is made for simplicity. The essential results follow through when a favorable court decisions makes the property right of the winning party more secure that it was before the court decision.
} 
probabilities but not necessarily only so. ${ }^{5}$ Even better, the two parties would prefer to commit to such a division for the indefinite future if they could find a way to prevent one another in the future from unilaterally paying the litigation fee and gaining access to the asset. But such a commitment is not credible in our setting, as it is not in many settings with unclear titles, and the parties could only settle in dividing only this period's asset returns under the threat of going to court.

Let $s$ denote the fraction of the asset return that goes to party $A$ with $1-s$ thus denoting the fraction that goes to party $B$. That is, if the two parties were to settle in this period, party $A$ would receive a current payoff of $s R$ while party $B$ would receive $(1-s) R$. There are many ways according to which bargaining could take place, but for simplicity we suppose that the two parties always split the surplus (or, given risk neutrality and symmetry, they use the Nash or any other symmetric bargaining solution). ${ }^{6}$ Let $s^{*}$ denote the corresponding Markov Perfect Equilibrium split of $R$, if the parties were to find one acceptable split. If that split were acceptable in this period, it would also be acceptable in all future periods and, therefore, the discounted continuation payoff of player $A$ would be $\delta\left(s^{*} R-L\right)+\delta^{2}\left(s^{*} R-L\right)+\cdots=\delta \frac{s^{*} R-L}{1-\delta}$ and similarly that for player $B$ would be $\delta \frac{\left(1-s^{*}\right) R-L}{1-\delta}$. The split-the-surplus rule implies that $s^{*}$ can be obtained by solving

$$
s^{*} R+\delta \frac{s^{*} R-L}{1-\delta}-V_{A}^{c}=\left(1-s^{*}\right) R+\delta \frac{\left(1-s^{*}\right) R-L}{1-\delta}-V_{B}^{c}
$$

Substituting in $V_{A}^{c}$ and $V_{B}^{c}$ defined in (1) and then simplifying, we arrive at

$$
\begin{aligned}
s^{*} R+\delta \frac{s^{*} R-L}{1-\delta}-\left(p \frac{R}{1-\delta}-C\right) & =\left(1-s^{*}\right) R+\delta \frac{\left(1-s^{*}\right) R-L}{1-\delta}-\left((1-p) \frac{R}{1-\delta}-C\right) \Rightarrow \\
2 s^{*} R+\delta \frac{2 s^{*} R-L}{1-\delta} & =R+\delta \frac{1 R-L}{1-\delta}-\frac{R}{1-\delta}+2 p \frac{R}{1-\delta} \Rightarrow \\
2 s^{*} \frac{1}{1-\delta} & =2 p \frac{1}{1-\delta} \Rightarrow \\
s^{*} & =p .
\end{aligned}
$$

\footnotetext{
${ }^{5}$ Going to court for both parties is always an equilibrium, regardless of whether a Markov Perfect Equilibrium with Settlement exists. In the remainder we concentrate on finding conditions under which an equilibrium with settlement holds.

${ }^{6}$ Another alternative simple bargaining subgame would involve having one party (say $A$ ) always make an offer with the other party being able only to accept or reject the offer. In such a case, the offering party would have an advantage beyond that of having a higher winning probablity. None of the results depend on the particular protocol of bargaining that is adopted.
} 
That is, the split-the-surplus settlement has the parties share the return $R$ is in accordance with the winning probabilities.

The question is whether and when the two parties choose to settle instead of going to court. To do that, they both need to prefer settlement to conflict. For litigant A, splitting the surplus with continuation payoff $V_{A}^{s}$ is better than going to court when

$$
\begin{aligned}
V_{A}^{s} & =p R+\delta \frac{p R-L}{1-\delta} \geq V_{A}^{c}=p \frac{R}{1-\delta}-C \\
& \Rightarrow C \geq \frac{\delta}{1-\delta} L .
\end{aligned}
$$

For litigant B:

$$
\begin{aligned}
V_{B}^{s} & =(1-p) R+\delta \frac{(1-p) R-L}{1-\delta} \geq V_{B}^{c}=(1-p) \frac{R}{1-\delta}-C \\
& \Rightarrow C \geq \frac{\delta}{1-\delta} L .
\end{aligned}
$$

In short, when $C \geq \frac{\delta}{1-\delta} L$, then both litigants prefer trial to settlement, and trial is the only equilibrium should both prepare. However, we note a technicality: because trial also results when just one chooses trial, there always exist an equilibrium in which both choose trial (conditional on both preparing). In effect, if one party chooses trial, there is nothing the other party can do to prevent it. So when $C<\frac{\delta}{1-\delta} L$, there exist multiple equilibria, but when $C \geq \frac{\delta}{1-\delta} L$ there is a unique equilibrium.

Further observe that, conditional on both preparing, whenever a settlement equilibrium exists it is Pareto efficient, and whenever it does not exist so that only possible equilibrium is going to court, then going to court is the Pareto efficient outcome. Going to court is efficient in the latter case because it resolves the property rights dispute and prevents future litigation expenditures.

From now on, we assume the parties can coordinate on the Pareto efficient equilibrium so that settlement is reached when it is preferred by both parties. We believe this is a reasonable assumption for two reasons. First, there is complete information, and the parties during pre-trial negotiation should be able to ascertain the best feasible settlement (e.g., Nash Bargaining). Second, there is experimental evidence that coordination on the Pareto efficient equilibrium is common in similar Hi-Lo games (see Bacharach 2006). 
We now give our first result.

Proposition 1 Suppose both parties pay the litigation fee. Then, settlement is more likely, and going to court less likely, to take place

(i) the higher is the court fee $C$;

(ii) the lower is the litigation fee L; and

(iii) the lower is the discount factor $\delta$.

A higher court fee increases the cost of going to court and therefore makes settlement more likely. A higher litigation fee, because it has to be paid every period in the case of settlement, effectively increases the cost of settlement. Because going to court, by clarifying property rights through precedence, eliminates the cost of paying these litigation fees in the future, having higher litigation fees makes going to court more attractive and thereby increases the likelihood of going to court. Finally, a higher discount factor increases the present value of the litigation fees that would be paid in the event of settlement and therefore also make going to court more likely.

\subsection{The Legal Preparation Decision}

Next consider the decision to prepare litigation. There are four possibilities: both prepare and go to trial; both prepare and settle; only one prepares; neither prepares. The simplest to consider is when neither prepares in every period, in which case each receives total payoff of 0 in each round. Given that neither prepares, a one-shot deviation to prepare yields payoff $R-L$. Not preparing is better when $0>R-L$, i.e., $L>R$.

Suppose a salient asset $(R \geq L)$ and that if both prepare then there is a legitimate threat of trial $\left(C<\frac{\delta}{1-\delta} L\right)$. Consider the case where both prepare and go to trial. For A, it is better to prepare and go to trial than not prepare when

$$
p \frac{R}{1-\delta}-L-C \geq 0
$$

For B, the condition is

$$
(1-p) \frac{R}{1-\delta}-L-C \geq 0
$$


For both to pay the litigation fee, it must be true that

$$
L+C \leq \min \left\{p \frac{R}{1-\delta},(1-p) \frac{R}{1-\delta}\right\},
$$

which because $p \geq \frac{1}{2}$ becomes

$$
L+C \leq(1-p) \frac{R}{1-\delta} .
$$

Thus, both prepare and go to trial when $C<\frac{\delta}{1-\delta} L$ and $L+C \leq(1-p) \frac{R}{1-\delta}$. Or, alternatively, when $\delta>\max \left\{\frac{C}{C+L}, \frac{C+L-(1-p) R}{C+L}\right\}$.

Keeping $C<\frac{\delta}{1-\delta} L$, now suppose one litigant prepares in each round, and the other does not prepare in each round. The preparer receives $\frac{1}{1-\delta}(R-L)$, and the non-preparer receives 0 . The preparer prefers to prepare as long as $R \geq L$. If $\mathrm{A}$ is the non-preparer, then not preparing is better than the deviation payoff when

$$
\begin{aligned}
0 & \geq-L+p \frac{R}{1-\delta}-C \Rightarrow \\
C & \geq p \frac{R}{1-\delta}-L .
\end{aligned}
$$

If $\mathrm{B}$ is the non-preparer, we need $(1-p) \frac{R}{1-\delta}-L<C$.

Now consider a salient asset $(R \geq L)$ but with no legitimate threat of trial $\left(\frac{\delta}{1-\delta} L>\right.$ $C)$. If both prepare, then A prefers preparing to a one-shot deviation to not prepare when

$$
\begin{aligned}
\frac{p R-L}{1-\delta} & \geq 0+\delta \frac{p R-L}{1-\delta} \Rightarrow \\
p R & \geq L .
\end{aligned}
$$

Similarly, B prefers preparing to a one-shot non-preparation when $(1-p) R \geq L$. With $p \geq \frac{1}{2}$, both preparing and settling is an equilibrium when $(1-p) R \geq L$.

Finally, consider when just one prepares with no legitimate threat of trial. The preparing receives $R-L$, and with salient asset, preparing is optimal with no challenge. If $\mathrm{A}$ is the non-preparer, then not preparing is better than the one-shot deviation when $0 \geq p R-L \Rightarrow L \geq p R$. While if $\mathrm{B}$ is the non-preparer, not preparing is better when $L \geq(1-p) R$.

The following proposition highlights some important findings from this analysis. Supporting details are in the Appendix. 
Proposition 2 Assume the asset is salient. Then:

(i) For high enough property rights protection (i.e., p sufficiently close to 1), the party with the weakest claim does not pay the litigation fee and the party with the higher claim prepares litigation to obtain effective possession of the asset, whether or not there is a legitimate threat of trial.

(ii) The property right will be contested when the property right is sufficiently insecure (i.e., $p$ sufficiently close to $\frac{1}{2}$ ).

(iii) Negotiated settlement occurs when the property rights are sufficiently insecure (i.e., $p$ sufficiently close to $\frac{1}{2}$ ) and when the shadow of the future is sufficiently short (i.e., $\delta$ sufficiently close to 0).

(iv) Trial occurs when the property rights are sufficiently insecure (i.e., $p$ sufficiently close to $\frac{1}{2}$ ) and when the shadow of the future is sufficiently long (i.e., $\delta$ sufficiently close to 1).

\subsection{Example 1}

Let $R=100, L=30$, and $C=20$, consider three property rights scenarios $p=0.5$, 0.75 , and 0.9 , and suppose two discount factors $\delta=0$ and 0.75 . The asset is salient, so at least one litigant will prepare. Moreover, the threat of litigation is not legitimate under the short horizon $(\delta=0)$, but it is under the long horizon $(\delta=0.75)$. Whether only one prepares or both prepare depends on the property rights security $p$.

Table 1 lists the various equilibria of this example by property rights security and horizon. When the property right is secure, only the owner prepares litigation. When the property right is sufficiently insecure, both prepare, and whether there is settlement or trial depends on the horizon. The litigants go to trial with sufficiently insecure property rights and a sufficiently long horizon. Figure 1 summarizes the above pictorially. The six dots in the figure correspond to the six parameter configurations. As we will see in the next section, this general pattern remains under many changes to the basic model. 


\section{Variations}

The findings of the illustrative model are robust to many changes in the model and for a variety of litigation settings. We now present two variations of the basic model. In the first variation, the two parties continue interacting over an infinite horizon but choose litigation efforts endogenously with the probability of winning in court being endogenous as well. In the second variation a long-term agent faces a series of short-term agents who could challenge the long-term party. This variation could apply to patent or intellectual property rights disputes.

\subsection{Endogenous Litigation Efforts}

Parties $A$ and $B$ interact the same way as before but now they choose particular levels of (non-negative) litigation efforts, $l_{A}$ and $l_{B}$. (We can think of the "litigation fee" $L$ as distinct from the litigation effort and as the cost of challenge, which for now we set for simplicity at 0.) These efforts can include the cost of hiring lawyers, paralegals, and researchers who would help with preparation, discovery, and arguments that could be used in the event of going to court but also as a tool during the process of bargaining in the event of settlement. The probability of winning in court now depends on the litigation efforts as well as on the degree of property rights enforcement. In particular, party $A$ 's probability of winning is:

$$
p\left(l_{A}, l_{B}\right) \equiv \begin{cases}\frac{\phi l_{A}}{\phi l_{A}+(1-\phi) l_{B}}, & \text { if } l_{A}+l_{B}>0 \\ \phi, & \text { otherwise. }\end{cases}
$$

Litigant $B$ 's probability of winning in court is $1-p\left(l_{A}, l_{B}\right)=\frac{(1-\phi) l_{B}}{\phi l_{A}+(1-\phi) l_{B}}$ when $l_{A}+l_{B}>0$ (and, otherwise, equals $1-\phi$ ). Note that when both parties choose the same level of litigation effort, their probabilities of winning are $\phi$ and $1-\phi$. The parameter $\phi$ has the same interpretation as the exogenous probability in the previous section, as the degree of property rights protection with a $\phi(>1 / 2)$ closer to 1 implying a greater ability of the court system to enforce property rights. In addition to the degree of property rights protection, the litigation efforts (e.g., the expenses on lawyers, research, discovery and so on) affect the probability of winning in court. 
As will be shown, the litigation efforts, through their effect on the probabilities of winning in court, also affect the bargaining power and the share of the returns each party receives when the parties settle.

Clark and Riis (1998) axiomatized this functional form for the probability of winning, which has been used in litigation settings in Farmer and Pecorino (1999), Bernardo et al. (2000), Hirshleifer and Osborne (2001), Robson and Skaperdas (2008), and, in a simpler form, dating back to Tullock (1980). Skaperdas and Vaidya (2012) provide a Bayesian derivation of this functional form, whereby the two parties expend their litigation efforts on evidence that will favor their cause and the judge or jury make inferences based on that evidence. ${ }^{7}$

In each period, the timing of the interaction of the two parties is as follows:

1. Levels of efforts, $l_{A}$ and $l_{B}$, are chosen simultaneously by the two parties.

2. The parties negotiate in the shadow of the court and possibly settle. If both parties choose to settle, the settlement takes place; otherwise, the case goes to court and each side pays the court fee $C$. Settlement follows the split-the-surplus rule (such as the Nash bargaining solution).

3. The payoffs for the period are realized. If there is a court decision, there is no further interaction between the two parties and the winner takes undisputed possession of the asset. If there is settlement, the game starts anew in the next period.

We consider the choices faced by the two parties at the beginning of stage 2 , after they have made specific choices, $\left(l_{A}, l_{B}\right)$, of litigation efforts. If the two parties were to go to court, their payoffs over the remaining horizon of the game would be the following:

$$
\begin{aligned}
V_{A}^{c} & =\frac{\phi l_{A}}{\phi l_{A}+(1-\phi) l_{B}}\left(R+\delta R+\delta^{2} R+\ldots\right)-C=\frac{\phi l_{A}}{\phi l_{A}+(1-\phi) l_{B}} \frac{R}{1-\delta}-C, \\
V_{B}^{c} & =\frac{(1-\phi) l_{B}}{\phi l_{A}+(1-\phi) l_{B}}\left(R+\delta R+\delta^{2} R+\ldots\right)-C=\frac{(1-\phi) l_{B}}{\phi l_{A}+(1-\phi) l_{B}} \frac{R}{1-\delta}-C .(3)
\end{aligned}
$$

\footnotetext{
${ }^{7}$ Another axiomatic derivation of more general functional forms is that of Rai and Sarin (2009) whereas Corchon and Dahm (2010) derive some other types of functional forms. Inderst et al. (2007) apply such functional forms to contests within organizations.
} 
To derive the payoff functions for the case of settlement, we first need to determine the shares of $R$ that each party would receive as a function of the litigation efforts. Continue denoting by $s$ the current-period share received by party $A$ and by $1-$ $s$ the share received by party B. In addition, let $s^{*}$ denote the Markov Perfect Equilibrium share that is to be received in subsequent periods if Settlement were to be an equilibrium and let $\left(l_{A}^{*}, l_{B}^{*}\right)$ denote the equilibrium efforts that would be chosen in the future. Then, conditional on the choice of $l_{A}$, the continuation payoff of party $A$ would be $s R+\frac{\delta\left(s^{*} R-l_{A}^{*}\right)}{1-\delta}$ and similarly for party $B(1-s) R+\frac{\delta\left(\left(1-s^{*}\right) R-l_{B}^{*}\right)}{1-\delta}$. The sharing rule based on the Nash bargaining solution (or any other symmetric bargaining solution) is determined by the $s$ that solves the following equation:

$$
s R+\frac{\delta\left(s^{*} R-l_{A}^{*}\right)}{1-\delta}-V_{A}^{c}=(1-s) R+\frac{\delta\left(\left(1-s^{*}\right) R-l_{B}^{*}\right)}{1-\delta}-V_{B}^{c} .
$$

The solution and the resultant sharing rule is

$$
s^{n}=\frac{\varphi l_{A}}{\phi l_{A}+(1-\phi) l_{B}} \frac{1}{1-\delta}+\frac{\left(l_{A}^{*}-l_{B}^{*}\right) / R-s^{*}}{1-\delta} .
$$

Note how the sharing rule depends on the degree of property rights protection parameter $\phi$ as well as on the litigation efforts of the two parties. Then, the payoff functions under settlement are as follows:

$$
\begin{aligned}
V_{A}^{s} & =s^{n} R+\frac{\delta\left(s^{*} R-l_{A}^{*}\right)}{1-\delta}-l_{A}, \\
V_{B}^{s} & =\left(1-s^{n}\right) R+\frac{\delta\left(\left(1-s^{*}\right) R-l_{B}^{*}\right)}{1-\delta}-l_{B} .
\end{aligned}
$$

With these payoff functions, the Markov Perfect Equilibrium litigation efforts under Settlement (provided such an equilibrium exists) are

$$
l_{A}^{*}=l_{B}^{*}=\phi(1-\phi) \frac{R}{1-\delta} .
$$

It turns out that the equilibrium litigation efforts when the two parties expect to go to court are also the same as under Settlement. (This identical level of litigation efforts across Settlement and going-to-Court implies that in any Markov Perfect Equilibrium there is no deviation in stage 1 regardless of whether Settlement or going-to-Court is the equilibrium choice in the second stage.) Note that the equilibrium litigation 
efforts depend on the whole discounted value of the asset's returns $\left(\frac{R}{1-\delta}\right)$ and the degree of property rights protection, with higher protection (i.e., higher $\phi$ ) inducing lower litigation efforts. In addition, the equilibrium probability of winning for party $A$ and the equilibrium share $s^{*}$ are both equal to $\phi$.

Settlement can be an equilibrium only if the continuation payoffs under settlement are higher for both parties or

$$
V_{A}^{s}\left(l_{A}^{*}, l_{B}^{*}\right)=\phi(1-2 \delta+\delta \phi) \frac{R}{(1-\delta)^{2}} \geq V_{A}^{c}\left(l_{A}^{*}, l_{B}^{*}\right)=\phi \frac{R}{1-\delta}-C
$$

and

$$
V_{B}^{s}\left(l_{A}^{*}, l_{B}^{*}\right)=(1-\phi)(1-\delta-\delta \phi) \frac{R}{(1-\delta)^{2}} \geq V_{B}^{c}\left(l_{A}^{*}, l_{B}^{*}\right)=(1-\phi) \frac{R}{1-\delta}-C .
$$

The two conditions hold only if

$$
C \geq \phi(1-\phi) \frac{R}{(1-\delta)^{2}}
$$

The following proposition summarizes the main findings of the game with endogenous litigation efforts.

Proposition 3 Consider the extended game in which both parties choose their level of litigation effort. Then, from (7), Settlement is more likely, and going to court less likely, to take place

(i) the higher is the court fee $C$;

(ii) the lower is the return on the asset $R$;

(iii) the lower is the discount factor $\delta$; and

(iv) the better is the protection of property rights (i.e., the closer $\phi$ is to 1).

As before, higher court costs make settlement more likely. While in the simpler model of the previous section the value of the asset did not affect the likelihood of settlement, now because it affects the level of litigation efforts it also affects the likelihood that the settlement equilibrium exists. A higher litigation fee, because it has to be paid every period in the case of settlement, effectively increases the cost of settlement. Because going to court, by clarifying property rights, eliminates the 
cost of paying these litigation fees in the future, higher litigation fees also increase the likelihood of going to court. The effect of a higher discount factor reducing the likelihood of settlement and making going to court more likely continues to hold in this extended setting. Finally, contrary to the case with exogenous probabilities of winning, the degree of property rights protection also affects the likelihood that a Settlement equilibrium exists, with better property rights protection increasing that likelihood.

\subsection{A Long-term Party Against a Series of Short-term Po- tential Challengers}

The models examined thus far involve two parties that are involved in a long-term legal but potentially decisive dispute. For example, they might have competing claims on a productive asset which they can exploit jointly under a series of short-term agreements (that is, under the Settlement outcome), backed by their respective litigation expenditures, or they could resolve once-and-for-all in court. We now examine a variation of the basic model with one long-term agent potentially facing a series of short-term agents who could sue the long-term agent for damages. This setting probably better fits patent or intellectual property rights disputes. We show how the main comparative-static result of the effect of the shadow of the future readily extends to such settings.

Consider a long-term agent $A$, with an indefinite horizon, who faces in each period a short-term potential challenger $b$ (each lasting one period) who could sue agent $A$ for the rights to a one-time payment of $R$. To sue $A$, a challenger would have to incur a fixed cost of $L>0$. If no court decision has taken place in the past, let $p$ denote the probability of winning in court of agent $A$, with $1-p$ thus representing the challenger's probability of winning. We suppose that $p \geq 1 / 2$ (so that $A$ can be thought of as having a better initial property right than the challengers). If sued, agent $A$ incurs a legal cost $L_{A}>0$ regardless of whether the two sides go to court or not; this cost can be thought of as the cost of hiring a legal team that would help $A$ with the possible settlement and pre-trial costs but also preparing for the eventuality of going to court. If the two sides were to go to court, both would incur an additional 
cost $c>0$.

We suppose that $A$ can make a Settlement offer to $b$, which the latter accepts or rejects. Once $b$ has sued (and has paid cost $L$ ), his expected payoff of going to court is

$$
U_{b}^{c}(p)=(1-p) R-c .
$$

$A$ could offer a payment $S_{o}=(1-p) R-c$ to $b$, which $b$ could accept, and thus settle or she could offer something less, which $b$ would reject, resulting in the two sides going to court. Let us now consider what could occur under the two possibilities.

First, if $A$ were to make the payment $S_{o}$ and then continue doing so to each future challenger, her payoff would be ${ }^{8}$

$$
\begin{aligned}
V_{A}^{s}(p) & =R-S_{o}+\sum_{t=1}^{\infty} \delta^{t}\left(R-S_{o}-L_{A}\right) \\
& =p R+c+\sum_{t=1}^{\infty} \delta^{t}\left(p R+c-L_{A}\right)=\frac{p R+c-\delta L_{A}}{1-\delta} .
\end{aligned}
$$

Note that for the challenger in each period to choose to sue, it must be the case that the settlement payment received from $A$ is higher than the cost of suing, or

$$
S_{o}=(1-p) R-c \geq L
$$

As this is the interesting case, we suppose that this condition is satisfied for the remainder of this section.

Going to court yields more complicated long-term outcomes. If the court decides in favor of $A$, then all future challengers $b$ face worse odds of winning in the future. Let $q_{h}(>p)$ denote $A$ 's future probability winning in court in the future. Conversely, if $A$ loses in court following an initial challenge, her future probability of winning decreases to $q_{l}(<p)$. To determine the expected payoffs of going to court, we thus need to determine the expected payoffs in the case of a court win and and in the case of a court loss.

Suppose that in the case of a win, $A$ would not be challenged in the future. (This could be assured if $L>\left(1-q_{h}\right) R-c$, the latter being the expected payoff of a

\footnotetext{
${ }^{8}$ Note that this value does not include the cost of $L$ which is considered to have been already paid. We continue the same practice in denoting values functions net of this cost below.
} 
(hallenger. $)^{9}$ Then, the value of having a probability of winning of $q_{h}$ from next period onward would be $\frac{R}{1-\delta}$.

In the case of a loss, there will always be a challenge given that $\left(1-q_{l}\right) R-c>(1-$ p) $R-c$ which by assumption is greater or equal than $L$. Then, there is the possibility of settlement and that of going to court, again, in that case. Suppose first the case of settlement. Each challenger $b$ would receive in each period a settlement payment $S_{l}=\left(1-q_{l}\right) R-c$, with the expected payoff of $A$, denoted $V_{B}^{s}\left(q_{l}\right)=\frac{R-S_{l}-L_{A}}{1-\delta}=$ $\frac{q_{l} R+c-L_{A}}{1-\delta}$. Therefore, if there is settlement when $A$ loses after going to court the first time, the expected payoff of going to court is

$$
V_{A}^{C s}(p)=p R-c+p \delta \frac{R}{1-\delta}+(1-p) \delta \frac{q_{l} R+c-L_{A}}{1-\delta} .
$$

In that case, $A$ will choose to go to Court if and only if ${ }^{10}$

$$
\begin{aligned}
V_{A}^{s}(p) & <V_{A}^{C s}(p) \Rightarrow \\
\frac{p R+c-\delta L_{A}}{1-\delta} & <p R-c+p \delta \frac{R}{1-\delta}+(1-p) \delta \frac{q_{l} R+c-L_{A}}{1-\delta} \Rightarrow \\
(2-\delta(2-p)) c & <\delta(1-p) q_{l} R+p L_{A} .
\end{aligned}
$$

Because both sides of this inequality are positive, the range of parameters that would result in going to court is larger the higher is $\delta$. In other words, the effect of the shadow of the future holds in this setting, a setting that involves less decisive conflict than that of the other model. Furthermore, the effects of the return of the asset $(R)$, or the cost of going to court $(c)$, and of the degree of protection of property rights $(p)$ are similar in the previous models we have examined.

These effects continue to hold under still richer variations of this setting. For example, if $A$ 's win probability, once it drops after a loss may later rise again after a win, then the shadow of the future effect still operates. We thus see that the shadow of the future looms large across many settings and how it can induce a party to go to court in equilibrium.

\footnotetext{
${ }^{9}$ If there were to be future challenges, similar results would be obtained.

${ }^{10}$ We suppose that Settlement occurs when the two payoffs are equal.
} 


\section{Experiment Design}

\subsection{Basics}

We conducted four experiment sessions at a large public university using university students as test subjects. The experiment was implemented via computer using the zTree experimental platform (Fischbacher 2007). The experimental laboratory recruits university students via emails and posted flyers. After learning of the laboratory, students register to be in the subject pool via a web site. When an experiment session is scheduled, the time and place of the experiment are posted on the recruiting web site, and an email with the time and place information is sent to students in the subject pool. Subjects then sign-up for that session via the recruiting web site. Subjects were allowed to participate in at most one session. Experiment decisions were made using "points" as the experimental currency. At the end of the experiment, the subject would exchange the points earned for actual U.S. currency. Each subject was given a $\$ 7$ show-up payment. The average total take-home amount (including show-up payment) was $\$ 24$ for about 75 minutes of participation. A total of 144 subjects participated. Only one student reported having a major related to law (Criminal, Law, and Society).

\subsection{Treatments and Sessions}

Our experiment implements the basic model from Section 2 but with a modification that converts the infinite horizon into a finite horizon with equivalent expected payoffs described in detail below. We vary two treatment variables: the degree of property rights $p$ and the dispute horizon $\delta$.

We consider the three levels of property rights security from the earlier example: $p=0.5,0.75$, and 0.9. We denote these insecure, moderate, and secure property rights, respectively. We also refer to these as the 50-50, 25-75, and 10-90 property rights scenarios.

We consider two dispute horizons, short and long, which also mimic those of the earlier example in Section 2.4. The short horizon consists of a single dispute over 100 points, which is equivalent to $\delta=0$. The long horizon consists of a dispute over a 
stream of four 100-point allotments, which is expected payoff equivalent to $\delta=0.75$.

Each session consisted of three phases: instructions, decisions, and questionnaire. The decisions phase entailed multiple matches (legal disputes), with each match consisting of a single, independent property rights dispute over an announced number of points. The degree of property rights was held fixed in each session, but the dispute horizon varied within each session. Specifically, the subjects engaged in 15 matches with short horizon and then 15 matches with long horizon. We can thus label the three sessions: 10-90, 25-75, and 50-50. A fourth session, labeled 50-50B, used 50-50 property rights with a more explicit representation of the expected payoffs than in the other three sessions. Basic information about the subjects that participated in each session is listed in Table 2 .

\subsection{Single Match, Short Horizon}

A single, short horizon match, denoted $T=1$, proceeds as follows.

First, the subjects are randomly and anonymously paired.

Second, each subject is given an endowment of 60 points and told her type, i.e., the probability that she would win a trial if a trial occurs. There are two "weak" types (10 and 25), one "equal" type (50), and two "strong" types (75 and 90), where strength corresponds to the percent chance of winning in court. These types are commonly known by the two subjects within each pair.

Third, each subject decides whether or not to prepare a legal case. The cost of preparing a legal case is 30 points. If both do not prepare cases, then each receives 0 points, and the match ends. If one subject prepares and the other does not, then the one that prepares receives all 100 points, which minus the 30 in fees, yields a total of 70 points. The non-preparer receives 0 points. If both prepare cases, then the match continues.

If the match continues, then a fourth stage is reached. An out-of-court settlement is proposed in which each party receives a share of the 100 points equal to her probability of winning in court (e.g., if a subject wins in court with probability $p$, then the proposed settlement has her receive $100 p$ points). Each subject decides whether to accept the proposed settlement or to go to court. If both accept the settlement, then 
each receives her respective settlement amount, and the match ends. If one or both decide to go to court, then the dispute goes to trial. Each subject pays a court fee of 20 points, and the winner of all 100 points is selected randomly by the computer according to the announced probabilities. The winner thus receives a final payment for the round of $100-30-20=50$. The loser receives none of the points for an total payment for the round of $0-30-20=-50$.

\subsection{Single Match, Long Horizon}

The long horizon $(T=4)$ dispute setting is structured to mimic a four-period dispute, where each period has 100 points disputed for a total of 400 points but simplified so that only one prepare-settle-court decision is made. Because out of court settlements do not have the permanence of court decisions, we assume that settling today yields preparation and settlement in each period, while non-preparation or a court ruling implies no future dispute. Specifically, a long horizon match proceeds as follows.

First, the subjects are randomly and anonymously paired.

Second, each subject is given an endowment of 240 points (60 points for each of the four presumed periods) and told the probability that she would win a trial if a trial occurs.

Third, each subject decides whether or not to prepare a legal case. The cost of preparing a legal case in the first period is 30 points. If both do not prepare cases, then each receives 0 points, and forgoes any claim on the points so the match ends. If one subject prepares and the other does not, then the one that prepares receives all 400 points, for a final payment of $400-30=370$. The non-preparer receives 0 points. If both prepare cases, then the match continues.

Fourth, if the match continues, then an out-of-court settlement is proposed in which each party receives a share of the first round's 100 points equal to her probability of winning in court. Reflecting the subgame perfect equilibrium, we further assume that the settlement agreed in the first period is replicated in the remaining three periods, so that in each of the last three periods each party receives $100 p_{i}$ points and pays 30 points, for a final payment in the match of $400 p_{i}-4(30)=400 p_{i}-120$. Each subject decides whether to accept the proposed settlement or go to court. If 
both accept the settlement, then each receives her settlement amount and the match ends. If one or both decide to go to court, then the dispute goes to trial, each subject pays a court fee of 20 points, the winner of all 400 points is selected randomly by the computer according to the announced probabilities to receive a final payment of $400-30-20=350$. The loser receives 0 points. A similar collapsing of multiple periods into a single decision was done by McBride and Skaperdas (2012).

\subsection{Other Details}

After arriving at the laboratory, the subjects are seated at computers. Each then reads the instructions (see Supplementary Materials) individually on her computer and answers two test questions. The instructions present the basic structure of the decision making environment. The endowment of points is given to prevent a subject from experiencing bankruptcy. An exchange rate of $\$ 0.035 /$ point ( $\$ 1$ per 25 points) was held constant in all experiments. Figure 2 displays the two decision screens. The order in which decisions are depicted in the table and in the decision buttons were randomly assigned to inhibit the creation of a focal decision. One match from the short horizon and one match from the long horizon are selected randomly by the computer, and each subject's earned payment comes from those two rounds. After the last match but before leaving the laboratory, each subject answered a brief questionnaire that asked for age, sex, major, year in school, number of economics courses taken, number of statistics courses taken, and so on (see Supplementary Materials). We use information from the questionnaire to obtain basic information about the subjects. No deception of any kind was used.

\subsection{Theoretical Predictions and Experiment Hypotheses}

The experiment parameters match in expected payoff terms the example from Section 2.4, so the equilibria described in Table 1 and Figure 1 provide the equilibrium predictions. The predicted dispute-level outcomes and individual-level strategies are more explicitly described in Table 3.

Observe that we predict different dispute outcomes under the different horizons 
and property rights regimes. The 10-90 setting has property rights sufficiently secure such that the increase in horizon leads to a change in off-path behavior but not onpath behavior. The 25-75 setting with intermediate property rights sees a more striking change. The increase in horizon induces a challenge by the weak party that yields a trial; that is, we see both a higher rate of pre-trial litigation preparation and an increase in trial incidence. Under the 50-50 setting, the property rights are sufficiently insecure to create high pre-trial litigation but not large enough to induce trial when the horizon is small, while under the large horizon, we see the same high level of pre-trial litigation but now trial-averting settlements cannot be reached.

Our first two experiment hypotheses follow.

Hypothesis 1 (Litigation Preparation) As the horizon increases from $\mathrm{T}=1$ to $\mathrm{T}=4$, the incidence of legal preparation will:

(a) not change under very secure property rights 10-90.

(b) increase under intermediate property rights 25-75.

(c) not change under insecure property rights 50-50.

Hypothesis 2 (Incidence of Trial on Path) As the horizon increases from $\mathrm{T}=1$ to $\mathrm{T}=4$, the overall incidence of trial will:

(a) not change under very secure property rights 10-90.

(b) increase under intermediate property rights 25-75.

(c) increase under insecure property rights 50-50.

Because the go-to-court decision may change off the equilibrium path in many treatment conditions, it is possible that over-preparation in those conditions may necessitate that the go-to-court decision be made. Our third hypothesis considers go-to-court decisions off the equilibrium path.

Hypothesis 3 (Incidence of Trial Off-path) As the horizon increases from $\mathrm{T}=1$ to $\mathrm{T}=4$ and conditional on both preparing, the incidence of trial will increase under each property rights regime. 
Dispute outcomes result from an interplay of two litigants' decision, but looking closer at the individual strategies can illuminate how the aggregated dispute outcome arises. Our next hypothesis considers individual strategies.

Hypothesis 4 (Individual Strategies) As the horizon increases from $\mathrm{T}=1$ to $\mathrm{T}=4$ :

(a) Type 10 subjects will switch from (not prepare, not court) to (not prepare, court).

(b) Type 25 subjects will switch from (not prepare, not court) to (prepare, court).

(c) Type 50, 75, and 90 subjects will switch from (prepare, not court) to (prepare, court).

\section{Results}

\subsection{Hypothesis 1: Incidence of Legal Case Preparation}

Figure 3 reports the average number of legal cases prepared per dispute for each session in all rounds, the average in the later rounds (8-15), and the prediction. In the secure (Session 10-90), insecure (50-50), and the short horizon of the moderately secure setting (25-75), the preparations align closely with the predicted levels (Session 50-50B results will be discussed separately below). In the long horizon of Session 25-75, the legal preparations are closer to 1 than the predicted 2.

Hypothesis 1 predicted that an increase in the horizon from short to long would not affect legal preparation in Sessions 10-90 and 50-50, but would increase legal preparation in 25-75. Visual inspection of the figures suggests confirmation of these qualitative results, and the hypothesis is more formally confirmed by the regressions presented in Table 4 and by non-parametric Wilcoxon rank sum tests (not shown for space limitations). The key variable is Dummy Long Horizon, which takes value 1 if the long horizon and takes value 0 if short horizon. A positive and statistically significant value for this coefficient implies that the incidence of trial is higher under the long horizon than under the short horizon. For additional perspective, Figure 
4 plots the time series of average prepared and average go to court (conditional on both preparing).

Thus, although there is much less legal preparation than predicted in the long horizon with moderate property rights (Session 25-75), the behavior largely matches the predicted qualitative change predicted in Hypothesis 1.

\subsection{Hypotheses 2 and 3: Incidence of Trial}

Changes in the incidence of trials due to a change in horizon present a mixed picture, as seen in Figure 5 and Table 5. While the overall (unconditional) incidence of trial increases under moderate property rights (25-75) as predicted, it is also the case that contrary to the prediction the overall incidence of trial increases under secure property rights (10-90) and has no change under insecure property rights (50-50). Wilcoxon tests yield the same picture (not shown).

An initial conclusion is that the predictions about overall incidence of trial are thus matched in only one of the three horizons. Closer examination, however, suggests some nuance. In the secure property rights setting (10-90), the unconditional incidence of trials is very low under both horizons (0.11 and 0.20, respectively), and even though it is a statistically significant increase, it is still close the equilibrium prediction of no trials under secure property rights. Thus, though the behavior in session 10-90 technically does not tightly match Hypothesis 1(a), the level behavior in that session is similar to the prediction.

Of course, the unconditional incidence of trials does not distinguish between the two kinds of decision errors. A trial results when each party chooses both to prepare and to go to court, so the overall measure reflects a conflation of both decisions. For example, the overall incidence of trials could go down even when the rate of going to court, conditional on both being prepared, goes up if the rate of legal preparation goes down to a sufficient degree. To more closely isolate the trial decisions, consider the incidence of trials conditional on both parties being prepared, with regression results in Panel B of Table 5 (figures not shown). These regressions, which more directly capture the incidence of trials among cases where trial is an immediate possibility, reveal that the change in conditional incidence of trial matches the prediction under 
the secure property rights (10-90) but only weakly matches under the moderately property rights (25-75). It does not match the prediction under insecure property rights (50-50).

The emergent picture is that behavior matches the theory fairly well with secure property rights, matches the theory less well but is somewhat consistent with moderately secure property rights, and does not match well with insecure property rights.

\subsection{Session 50-50B}

There are various possible reasons why behavior in the insecure property rights setting differs dramatically from the prediction. One is that the subjects in the 50-50 session had unobserved preferences that were systematically different than the other subjects and the assumed utility functions of the model. Such would be the case if, for example, the 50-50 subjects got a large thrill from going to court that swamped out other incentives, thus making their behavior unresponsive to the change in payoffs. That experimental subjects in contests are more aggressive than assumed in expected payoff maximization models (Dechenaux et al. 2012) is evidence that this possibility should not be immediately dismissed.

However, we contend that another explanation is warranted for two reasons. First, because we find a response to the expected payoffs as the horizon changes in the 1090 and 25-75 sessions, and because the subjects are randomly assigned the property rights treatments, it is unlikely that the pattern merely reflects a property of the sample size. Second, attributing the anomalous behavior to other psychological factors closes the door on other viable alternative explanations that could lend new insights into the incidence of trial.

We here explore one such alternative, namely, that the expected payoff calculation in the 50-50 setting is less transparent than in the 25-75 and 10-90 settings, thus resulting in more behavior that differs substantially from the predicted behavior. In effect, the expected payoff calculations for the secure and moderate property rights setting are more transparent because the asymmetry in strength makes the dispute decisions more easy to identify. For example, it is clear to a weak party to not 
challenge a strong party when the horizon is short. Even if the subjects in the 10-90 and 25-75 settings are imprecise in calculating expected payoffs, then they may still intuit a decision relatively close to optimal. In the symmetric 50-50 case, however, the subject cannot use the asymmetry to aid in identifying an appropriate strategy but must instead make an expected payoff calculation. In presenting the information about payoffs to the subjects, we did not report expected payoffs but rather reported probabilities and outcome-contingent payoffs. The subject must then calculate the expected payoff for herself.

We conducted the 50-50B session to explore this possibility. The 50-50B session is identical to the 50-50 session except the subjects are also shown an explicit expected payoffs table when making their decision. We thus have the following conjecture:

\section{Hypothesis 5 (Expected Payoff Clarity) Behavior in Session 50-50B} will more closely match the predictions of Hypotheses 1-3 than behavior in Session 50-50.

Figures 3 and 5 and Tables 4 and 5 report the observed behavior from Session 50-50B. As expected, we see a sharper change in the incidence of trial as the horizon is increased in the 50-50B session than in the original 50-50 session. Overall, the behavior in 50-50B matches Hypotheses 2 and 3 much better than the 50-50 behavior. This is strong evidence that clarity in the expected payoff brings behavior more closely in line with the theoretical predictions.

The behavior matches Hypothesis 1 less well, though, we argue, adequately well. The prediction is no change in legal case preparation as the horizon increases under insecure property rights, and we see a statistically significant increase. This is due to a smaller level of preparation in the short horizon in 50-50B than in 50-50, as seen in Figures 3(c) and 3(d). We note, however, that despite this drop, the level of preparation is still very high and close to the predicted level. Why the preparation is lower in the 50-50B short horizon than in the 50-50 short horizon is not clear, but we interpret the overall evidence as largely consistent with our prediction. 


\subsection{Hypothesis 4: Individual Strategies}

Because the court decision is only made if both litigants prepared legal cases, there will be cases where we cannot know for sure what a subject would have done if presented with a litigation choice. Perfect identification of complete strategies is thus impossible in our multistage game.

This difficulty is seen in Table 6, which presents the proportion of subjects that selected different observable choice patterns. Choices that would be observed if both litigants played the predicted strategy are boxed by single lines. Double lines box the choice that would be observed by a subject when she chose the predicted strategy but the other subject did not.

Under the short horizon $(\mathrm{T}=1)$, we see observed choices match predicted observed choices around $70 \%$ of the time for all subject types in the 10-90, 25-75, and 50-50B sessions. Including appropriate off-path behavior raises it to as much as $90 \%$ for the strong litigant in the 10-90 session. The exception is the 50-50 session, which as discussed earlier, may be explained by poor expected payoff calculations.

Under the long horizon $(\mathrm{T}=4)$, observed behavior matches observed predicted behavior about $80 \%$ of the time in the secure property rights setting. In other settings, however, we see deviations from the prediction. In the moderate setting (25-75), a large number of weak litigants (58\%) do not prepare legal cases. Many strong litigants thus do not have to make the go to court decision. Those that do overwhelmingly choose to go to court as predicted, which indicates that it is the weak litigants that are deviating from prediction and not the strong litigants. The picture differs with insecure property rights. The equally strong litigants both prepare as predicted, but they also avoid court when they should not.

The trial decisions tell a similar story but with nuance because many of these choices occur off the predicted equilibrium path and have small numbers. Behavior matches prediction in all cases except strong litigants too frequently go to court when they should not under moderate property rights with short horizon. Given that there are very few observations for this case, we cannot ascertain whether this is a result of the small sample or some other systematic behavioral pattern such as overconfidence. 


\section{Conclusion}

This paper presents an explanation for why trials may occur with complete information. The legal precedent created by trial, if it significantly alters the property right of the winner, creates an incentive for litigants to forgo out-of-court settlements in favor of trial that prevents future litigation costs. A game theoretic model reveals that litigants choose trial when the initial property rights are insecure and when the horizon of profits created by the disputed asset is long. Subjects in a laboratory experiment behave consistently with many of the model's predictions, though we identify lack of clarity about the payoffs as one reason why behavior may diverge from the prediction.

Future work can build on our work in various ways. For example: How does the possibility of appeal affects the incentives to go to trial? How does the presence of multiple trials constrain an actor's ability to succeed in all trials? And how might the possibility of arbitration that creates temporary property rights affect the incidence of trial? Work in these new directions can build on our work to better understand the incidence of trial in complete information settings.

\section{APPENDIX}

This appendix contains details relevant for Proposition 2. The conditions obtained in Section 2.3 yield the following equilibria:

1. If $R<L$, then the asset is not salient, and the unique equilibrium is neither prepares.

2. If $R>L$ so the asset is salient, then:

(a) If $C<\frac{\delta}{1-\delta} L$ so the threat of trial is legitimate, then:

i. If $C>p \frac{R}{1-\delta}-L$ then there is an equilibrium in which $\mathbf{A}$ does not prepare and B prepares.

ii. If $C>(1-p) \frac{R}{1-\delta}-L$, then there is an equilibrium in which $\mathbf{A}$ prepares and B does not prepare. 
iii. If $C<(1-p) \frac{R}{1-\delta}-L$, then there is an equilibrium in which both prepare and go to trial.

(b) If $C>\frac{\delta}{1-\delta} L$ so there is no legitimate threat of trial, then:

i. If $L>p R$, then there is an equilibrium in which $\mathbf{A}$ does not prepare and B prepares.

ii. If $L>(1-p) R$, then there is an equilibrium in which $\mathbf{A}$ prepares and $\mathrm{B}$ does not prepare.

iii. If $L<(1-p) R$, then there is an equilibrium in which both prepare and settle out of court.

\section{References}

[1] Bacharach, Michael. 2006. Beyond Individual Choice: Teams and Frames in Game Theory. Princeton University Press.

[2] Bebchuk, Lucian. 1984. "Litigation and Settlement under Imperfect Information." Rand Journal of Economics 15: 404-415.

[3] Bester, Helmut and Kai A. Konrad. 2004. "Delay in Contests" European Economic Review 48: 1169-1178.

[4] Bibas, Stephanos. 2004. "Bargaining Outside the Shadow of Trial." Harvard Law Review 117: 2463-2547.

[5] Birkeland, Sigbjorn. 2013. "Negotiation under Possible Third-party Resolution." Journal of Law and Economics 56: 281-299.

[6] Buchanan, James. 1989. "Notes on Irrelevant Externalities, Enforcement Costs, and the Atrophy of Property Rights," in Tollison, R. and Vanberg, V. (eds) Explorations Into Constitutional Economics. College Station: Texas A\&M University Press.

[7] Che, Yeon-Koo and Jong Goo Yi. 1993. "The Role of Precedents in Repeated Litigation." Journal of Law, Economics, and Organization 9: 399-424.

[8] Clark, Derek J. and Christian Riis. 1998. "Contest Success Functions: An Extension" Economic Theory 11: 201-204.

[9] Cooter, Robert, Stephen Marks, and Robert Mnookin. 1982. "Bargaining in the Shadow of the Law: A Testable Model of Strategic Behavior." Journal of Legal Studies 11: 225-251. 
[10] Corchon, Luis and Matthias Dahm. 2010. "Foundations for Contest Success Functions." Economic Theory 43: 81-98.

[11] Dechenaux, Emmanual, Dan Kovenock, and Roman Sheremeta. 2012. "A Survey of Experimental Research on Contests, All-Pay Auctions, and Tournaments." Manuscript.

[12] Farmer, Amy and Paul Pecorino. 1999. "Legal Expenditure as a Rent Seeking Game." Public Choice 100: 271-288.

[13] Fischbacher, Urs. 2007. "z-Tree: Zurich Toolbox for Read-made Economic Experiments." Experimental Economics 10: 171-178.

[14] Fiss, Owen. 1984. "Against Settlement." Yale Law Journal 93: 1073-1090.

[15] Garfinkel, Michelle and Stergios Skaperdas. 2000. "Conflict Without Misperception or Incomplete Information: How the Future Matters." Journal of Conflict Resolution 44: 793-807.

[16] Gould, John. 1973. "The Economics of Legal Conflicts." Journal of Legal Studies 2: 279-300.

[17] Gross, Samuel and Kent Syverud. 1991. "Getting to No: A Study of Settlement Negotiations and the Selection of Cases for Trial." Michigan Law Review 90: 319-393.

[18] Grossman, Sanford and Oliver Hart. 1986. "The Costs and Benefits of Ownership: A Theory of Vertical and Lateral Integration." Journal of Political Economy 94: 691-719.

[19] Hart, Oliver and John Moore. 1990. "Property Rights and the Nature of the Firm." Journal of Political Economy 98: 1119-1158.

[20] Hewitt, David. 2012. "Strategic Litigation: A Theoretical and Experimental Study." Manuscript.

[21] Hirshleifer, Jack and Evan Osborne. 2001. "Truth, Effort and the Legal Battle." Public Choice 108: 169-195.

[22] Inderst, Roman, Holger M. Mueller, and Karl Warneryd. 2007. "Distributional Conflict in Organizations" European Economic Review 51: 385-402.

[23] Kennan, John and Robert Wilson. 1993. "Bargaining with Private Information." Journal of Economic Literature XXXI: 45-104.

[24] Landes, William. 1971. "An Economic Analysis of the Courts." Journal of Law and Economics 14: 61-107.

[25] Lanjouw, Jean and Josh Lerner. 1998. "The Enforcement of Intellectual Property Rights: A Survey of the Empirical Literature." Annales d'Economie et de Statistique (49-50): 223-246.

[26] Lederman, Leandra. 1999. "Which Cases Go to Trial?: An Empirical Study of Predictors of Failure to Settle." Case Western Reserve Law Review 49: 315-358. 
[27] Loewenstein, George, Samuel Issacharoff, Colin Camerer, and Linda Babcock. 1993. "Self-serving Assessments of Fairness and Pretrial Bargaining." Journal of Legal Studies 22: 135-159.

[28] McBride, Michael and Stergios Skaperdas. Forthcoming. "Conflict, Settlement, and the Shadow of the Future." Journal of Economic Behavior and Organization.

[29] Mnookin, Robert and Lewis Kornhauser. 1979. "Bargaining in the Shadow of the Law: The Case of Divorce." Yale Law Journal 88: 950-997.

[30] Priest, George and Benjamin Klein. 1984. "The Selection of Disputes for Litigation." Journal of Legal Studies 13: 1-55.

[31] Posner, Richard. 1973. "An Economic Approach to Legal Procedure and Judicial Administration." Journal of Legal Studies 2: 399-458.

[32] Powell, Robert. 2006. "War as a Commitment Problem." International Organization 60: 169-203.

[33] Rai, Birendra and Rajiv Sarin. 2009. "Generalized Contest Success Functions." Economic Theory 40: 139-149.

[34] Reinganum, Jennifer and Louis Wilde. 1986. "Settlement, Litigation, and the Allocation of Litigation Costs." Rand Journal of Economics 17: 557-568.

[35] Robson, Alexander and Stergios Skaperdas. 2008. "Costly Enforcement of Property Rights and the Coase Theorem." Economic Theory 36: 109-128.

[36] Shavell, Steven. 1982. "The Social Versus the Private Incentive to Bring Suit in a Costly Legal System." Journal of Legal Studies 11: 333-339.

[37] Shavell, Steven. 1998. "Contracts" pp. 436-445 in Newman, P., The New Palgrave Dictionary of Economics and the Law, Macmillan and Stockton Press.

[38] Skaperdas, Stergios and Samarth Vaidya. 2012. "Persuasion as a Contest." Economic Theory 51:465-486.

[39] Smith, Adam, et al. 2014. "The Costs of Conflict." Journal of Economic Behavior and Organization 97: 61-71.

[40] Spier, Kathryn. 2007. "Litigation," pp. 259-342 in Polinsky, A.M. and Shavell, S., Handbook of Law and Economics, Volume 1. Elsevier.

[41] Stanley, Linda and Don Coursey. 1990. "Empirical Evidence on the Selection Hypothesis and the Decision to Litigate or Settle." Journal of Legal Studies 19: $145-172$.

[42] Tullock, Gordon. 1980. Trials on Trial: The Pure Theory of Legal Procedure. Columbia University Press.

[43] Wärneryd, Karl. 2000. "In Defense of Lawyers: Moral Hazard as an Aid to Cooperation." Games and Economic Behavior 33: 145-158. 
Table 1: Equilibria by Property Rights Security and Horizon, Example 1

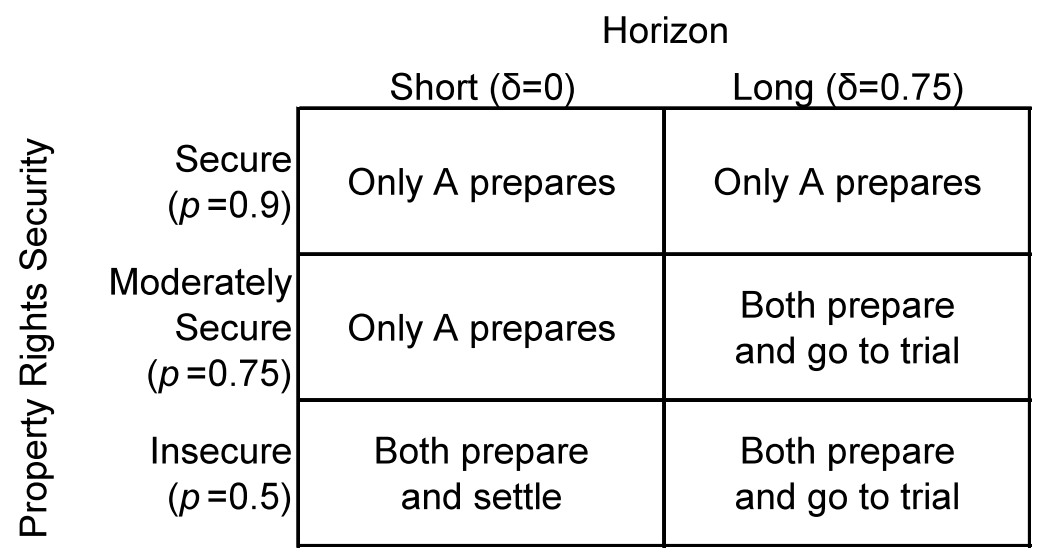


Figure 1: Equilibria in $(p, \delta)$-space, Example 1

(a) Settle-or-trial Decision

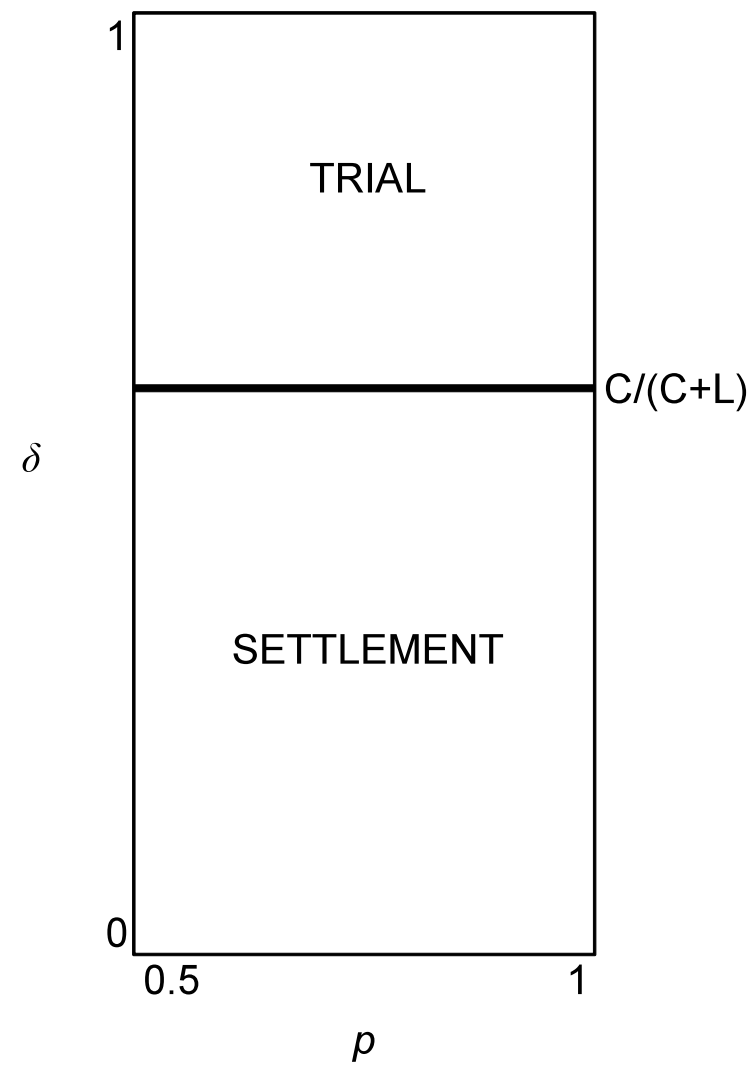

(b) Prepare Decision Conditional on Optimal Settle-or-trial Decision

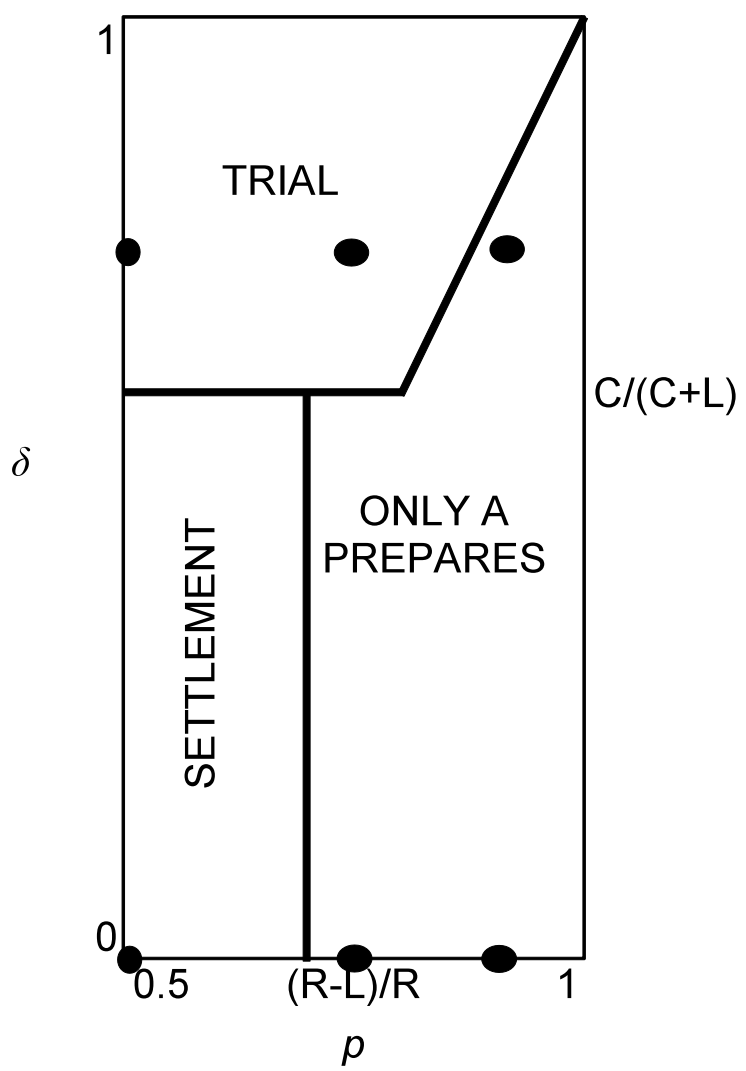

Notes: The example uses $R=100, L=30$, and $C=20$. The six dots in (b) correspond to the six treatment conditions in the experiment. The slope of the line in the upper right region of $(b)$ equals $(C+L-(1-p) R) /(C+L)$. 
Table 2: Subject Information, by Session

\begin{tabular}{|c|c|c|c|c|c|c|c|c|c|}
\hline \multirow[b]{2}{*}{ Session } & \multirow[b]{2}{*}{$\begin{array}{c}\text { Number } \\
\text { of } \\
\text { subjects }\end{array}$} & \multirow[b]{2}{*}{$\begin{array}{c}\text { Percent } \\
\text { male* }^{*}\end{array}$} & \multirow{2}{*}{$\begin{array}{l}\text { Percent } \\
\text { with 1+ } \\
\text { statistics } \\
\text { courses* }\end{array}$} & \multicolumn{5}{|c|}{ Percent with Major* } & \multirow[b]{2}{*}{$\begin{array}{l}\text { Average } \\
\text { take-home } \\
\text { earnings** }\end{array}$} \\
\hline & & & & $\begin{array}{l}\text { Business } \\
\text { or Econ. }\end{array}$ & $\begin{array}{c}\text { Other } \\
\text { Social } \\
\text { Science }\end{array}$ & $\begin{array}{l}\text { Physical } \\
\text { Science or } \\
\text { Engineer. }\end{array}$ & $\begin{array}{c}\text { Life Science } \\
\text { or Biology }\end{array}$ & $\begin{array}{c}\text { Humanities } \\
\text { or Undec. }\end{array}$ & \\
\hline All & 144 & $49 \%$ & $57 \%$ & $12 \%$ & $13 \%$ & $37 \%$ & $29 \%$ & $9 \%$ & $\$ 23.50$ \\
\hline $10-90$ & 38 & $61 \%$ & $50 \%$ & $13 \%$ & $8 \%$ & $50 \%$ & $18 \%$ & $11 \%$ & $\$ 24.59$ \\
\hline $25-75$ & 32 & $38 \%$ & $63 \%$ & $3 \%$ & $19 \%$ & $34 \%$ & $34 \%$ & $9 \%$ & $\$ 23.93$ \\
\hline $50-50$ & 36 & $56 \%$ & $61 \%$ & $8 \%$ & $11 \%$ & $50 \%$ & $28 \%$ & $3 \%$ & $\$ 22.92$ \\
\hline $50-50 B$ & 38 & $39 \%$ & $55 \%$ & $21 \%$ & $16 \%$ & $13 \%$ & $37 \%$ & $13 \%$ & $\$ 22.61$ \\
\hline
\end{tabular}

Notes: * denotes information obtained from the questionnaire. ${ }^{* *}$ includes the $\$ 7$ show-up payment. Total percent of majors per session might not add to $100 \%$ due to round-off error. 


\section{Figure 2: Experiment Display Screen-shots}

\section{A: Preparation Decision Screen-shot}

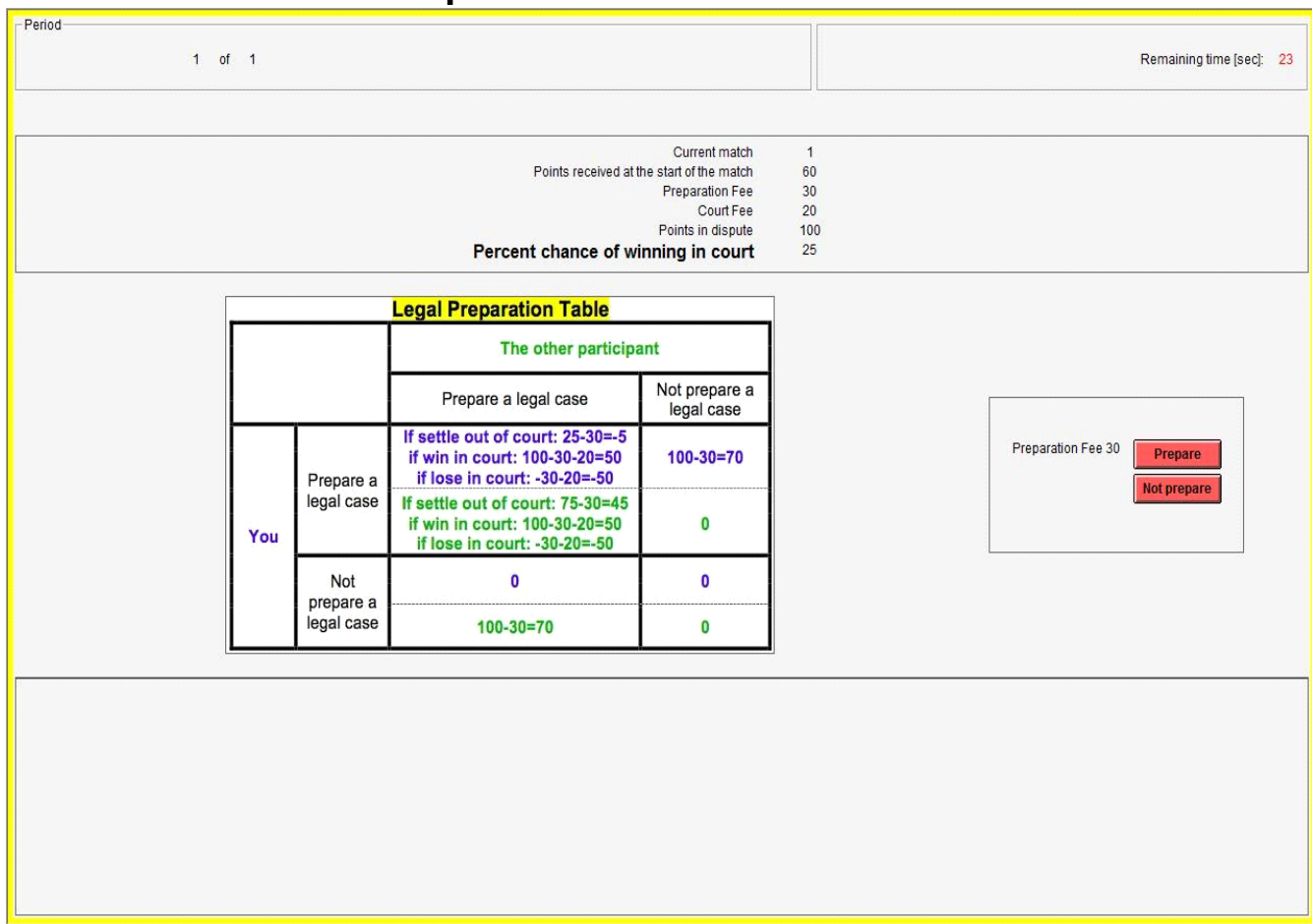

B: Court Decision Screen Shot

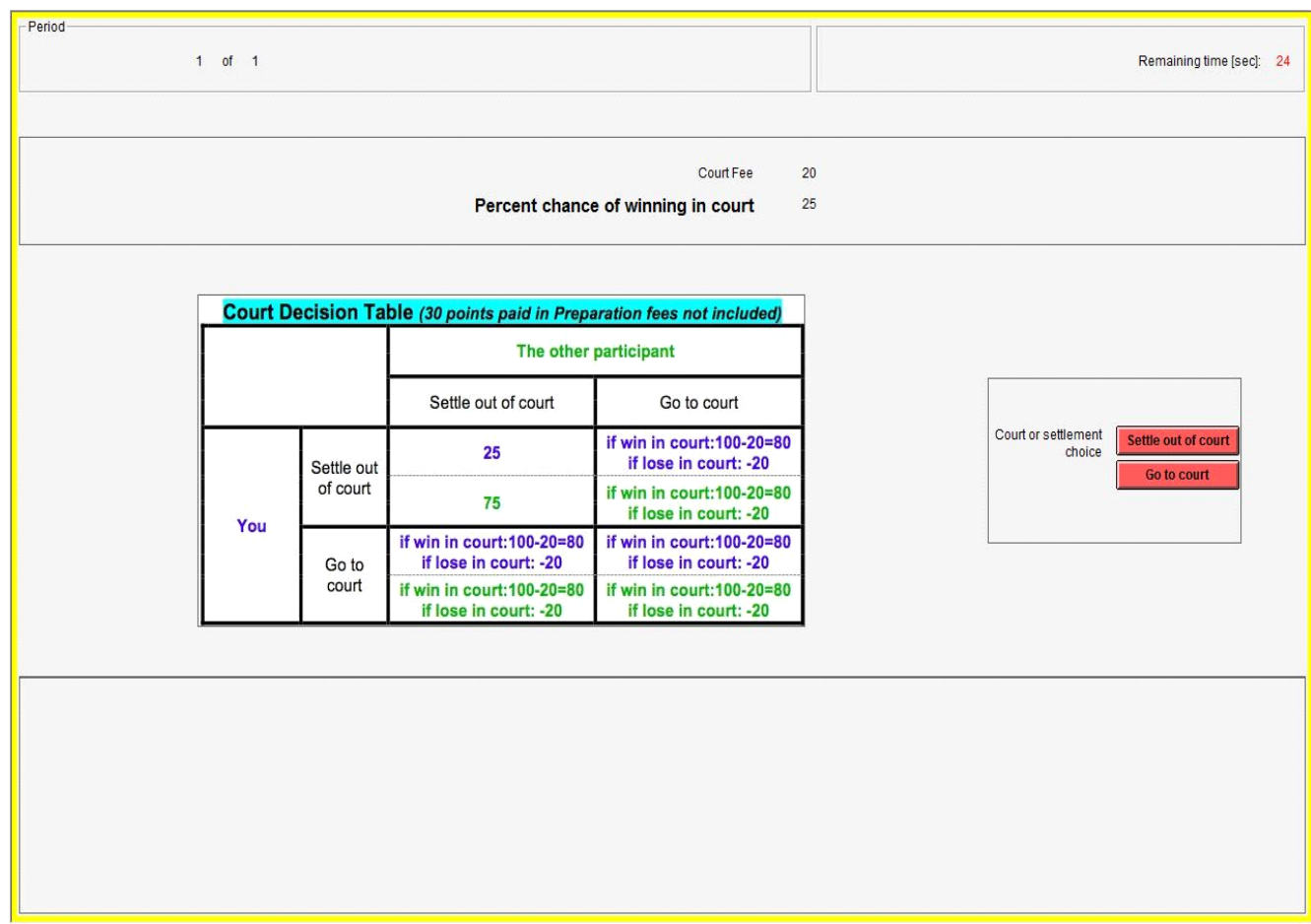


Table 3: Experiment Predictions

A: Dispute-level Outcomes

\begin{tabular}{|c|c|c|c|c|c|c|c|c|}
\hline \multirow[t]{2}{*}{ Session } & \multicolumn{2}{|c|}{$\begin{array}{c}\text { Number of } \\
\text { Prepared Cases }\end{array}$} & \multicolumn{2}{|c|}{$\begin{array}{l}\text { Proportion with } \\
\text { Both Prepared }\end{array}$} & \multicolumn{2}{|c|}{$\begin{array}{c}\text { Proporotion Go To } \\
\text { Court, } \\
\text { Unconditional }\end{array}$} & \multicolumn{2}{|c|}{$\begin{array}{l}\text { Proportion that Go } \\
\text { To Court, } \\
\text { Conditional }\end{array}$} \\
\hline & $\bar{T}=1$ & $T=4$ & $\mathrm{~T}=1$ & $\bar{T}=4$ & $\mathrm{~T}=1$ & $T=4$ & $\mathrm{~T}=1$ & $T=4$ \\
\hline $10-90$ & 1 & 1 & 0 & 0 & 0 & 0 & 0 & 1 \\
\hline $25-75$ & 1 & 2 & 0 & 1 & 0 & 1 & 0 & 1 \\
\hline $50-50$ & 2 & 2 & 1 & 1 & 0 & 1 & 0 & 1 \\
\hline
\end{tabular}

B: Individual-level

Strategies

\begin{tabular}{|c|cc|}
\hline Subject & \multicolumn{2}{|c|}{ Strategy } \\
\cline { 2 - 3 } Type & $\mathrm{T}=1$ & $\mathrm{~T}=4$ \\
\hline 10 & $\mathrm{NP}, \mathrm{NC}$ & $\mathrm{NP}, \mathrm{C}$ \\
90 & $\mathrm{P}, \mathrm{NC}$ & $\mathrm{P}, \mathrm{C}$ \\
\hline 25 & $\mathrm{NP}, \mathrm{NC}$ & $\mathrm{P}, \mathrm{C}$ \\
75 & $\mathrm{P}, \mathrm{NC}$ & $\mathrm{P}, \mathrm{C}$ \\
\hline 50 & $\mathrm{P}, \mathrm{NC}$ & $\mathrm{P}, \mathrm{C}$ \\
\hline
\end{tabular}


Figure 3: Average Litigation Preparation, by Session and Horizon
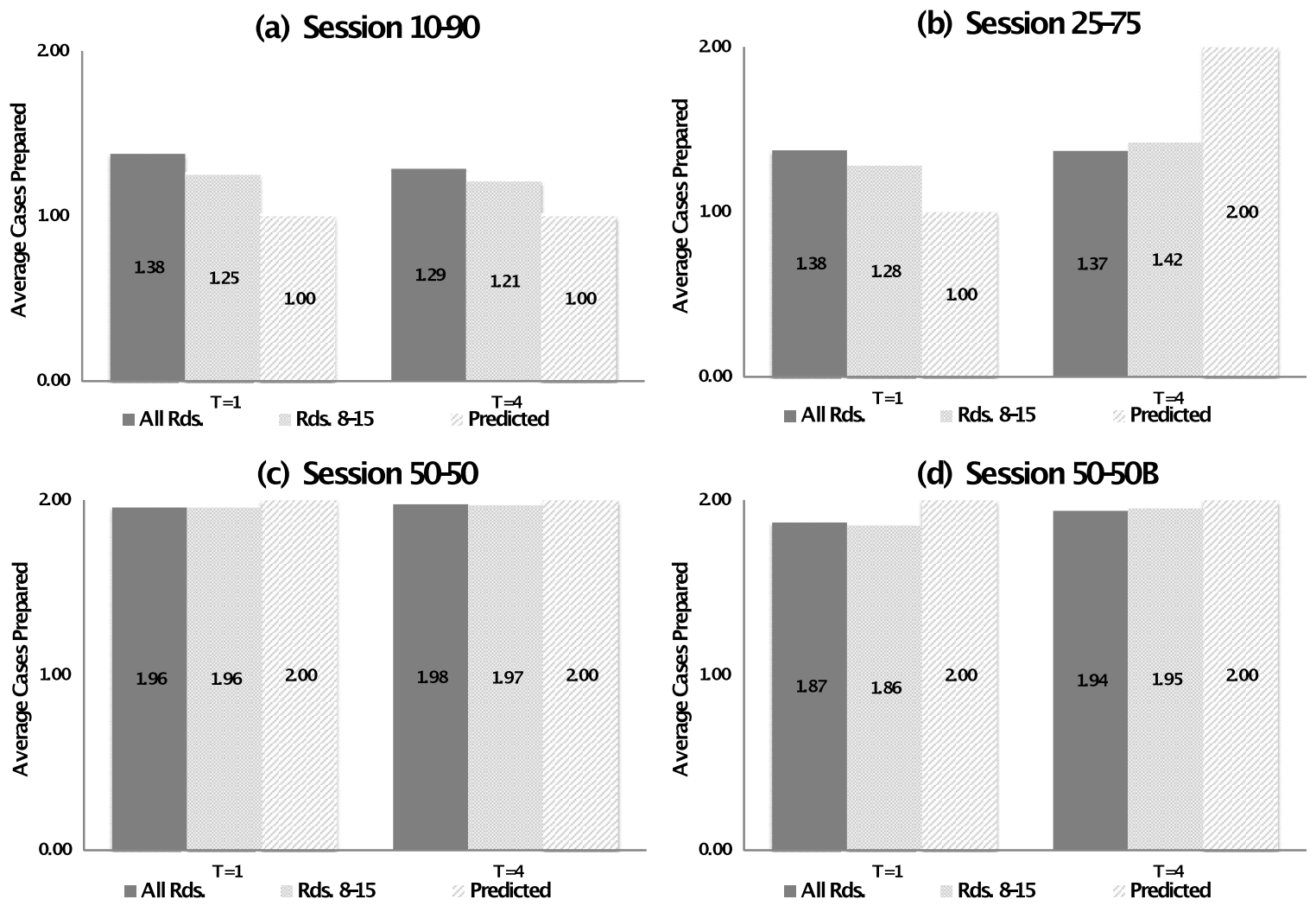
Table 4: Preparation Regression Estimates, by Session (Rounds 8-15)

\begin{tabular}{|c|c|c|c|c|}
\hline Session & $10-90$ & $25-75$ & $50-50$ & $50-50 \mathrm{~B}$ \\
\hline & & & & \\
Constant & $1.25^{* * *}$ & 1.28 & $1.96^{* * *}$ & $1.86^{* * *}$ \\
& $(0.04)$ & $(0.04)$ & $(0.02)$ & $(0.02)$ \\
& & & & $0.10^{* * *}$ \\
Dummy Long & -0.04 & $0.14^{* *}$ & 0.01 & $(0.03)$ \\
Horizon & $(0.05)$ & $(0.04)$ & $(0.02)$ & \\
& & & & 304 \\
\hline
\end{tabular}

Notes. Standard errors in parenthses. *, **, and *** denote significance at the $10 \%$ $5 \%$, and $1 \%$ levels, respectively. 
Figure 4: Time Series by Property Rights

3.A.1: Percent Prepare, Type 10
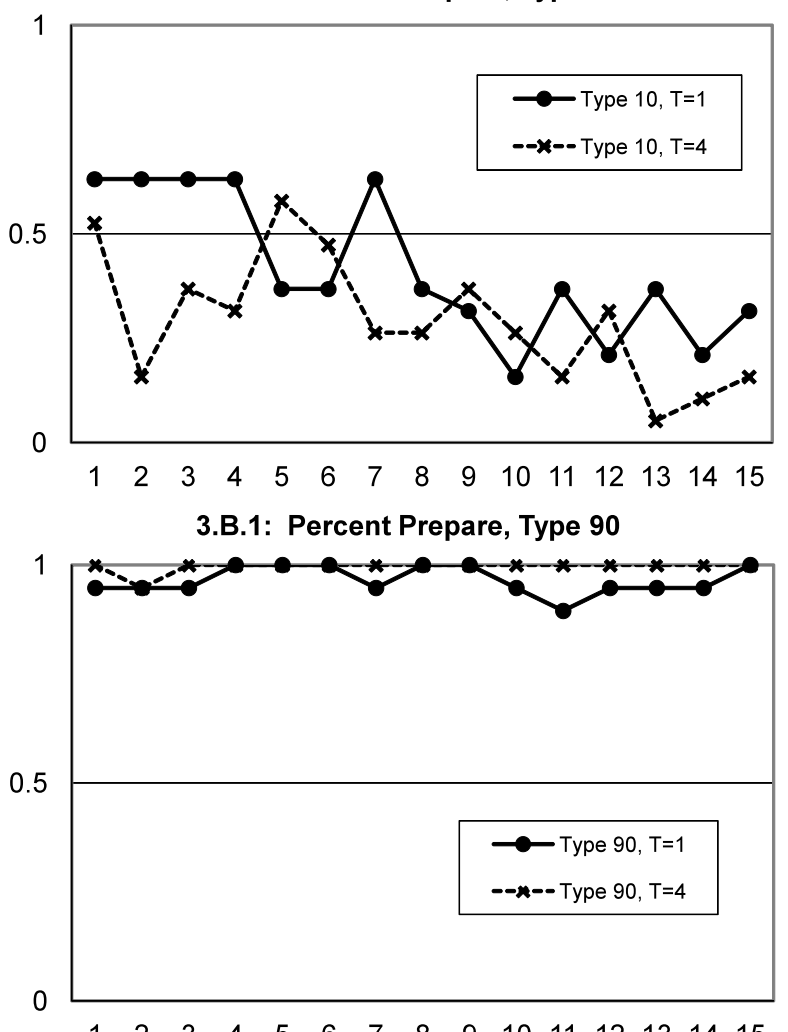

3.C.1: Percent Prepare, Type 25

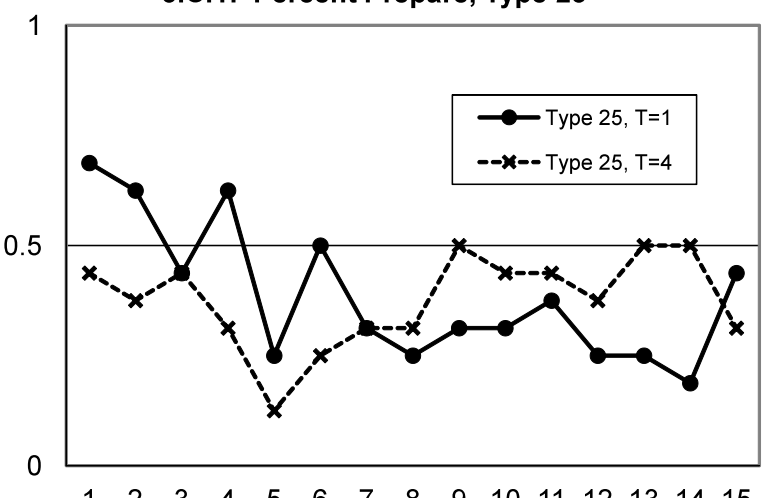

3.D.1: Percent Prepare, Type 75

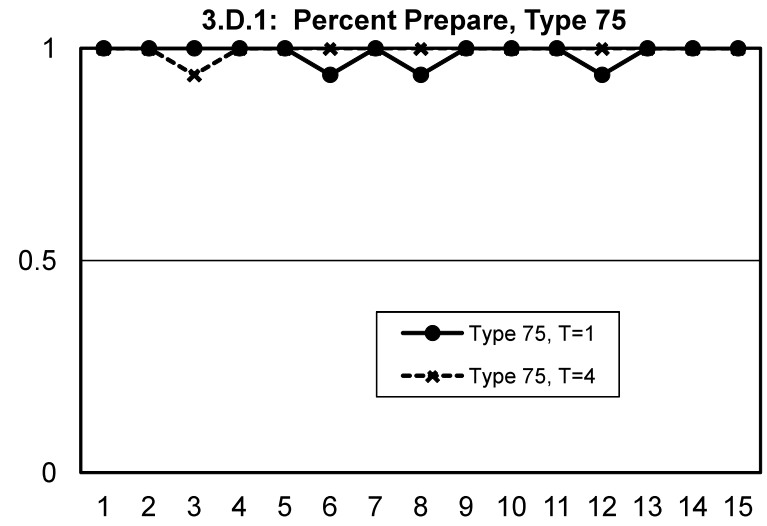

3.A.2: Percent Go to Court, Type 10

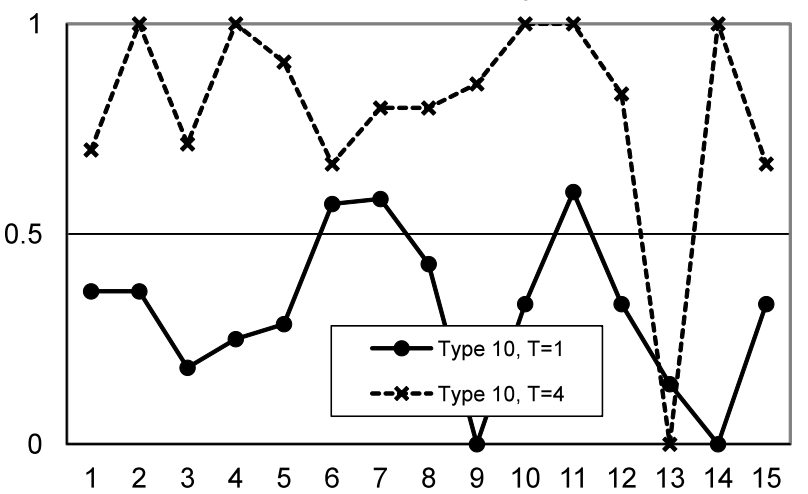

3.B.2: Percent Go to Court, Type 90

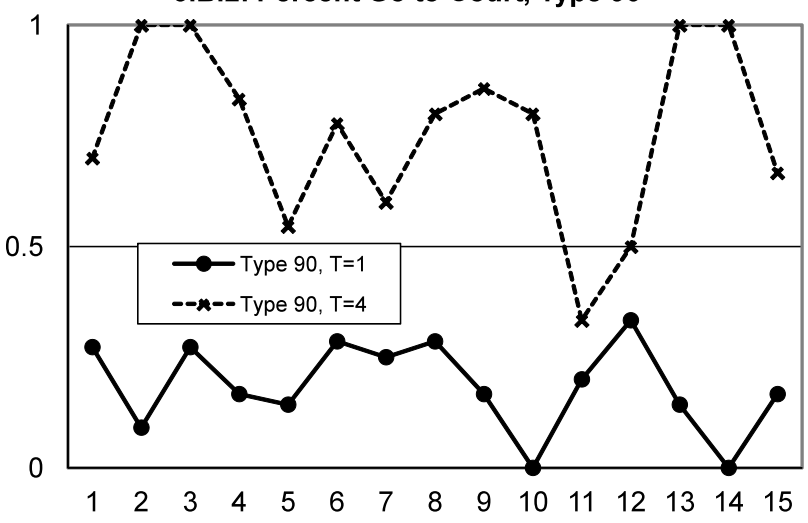

3.C.2: Percent Go to Court, Type 25

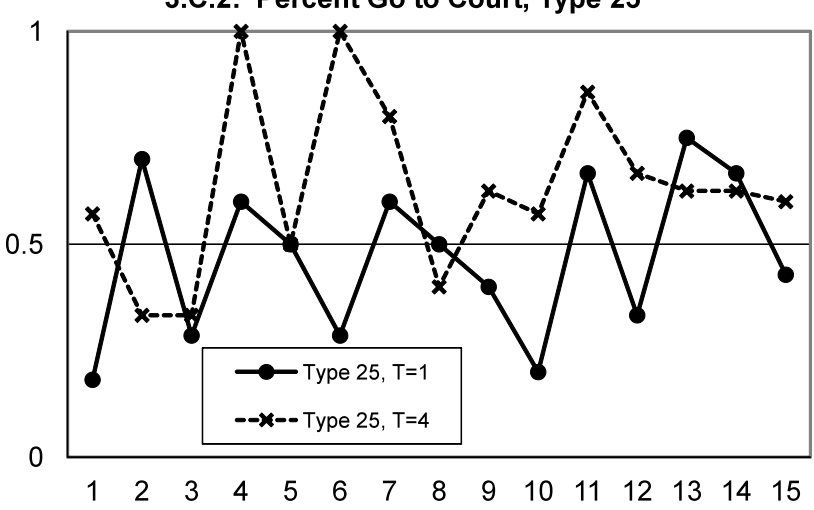

3.D.2: Percent Go to Court, Type 75

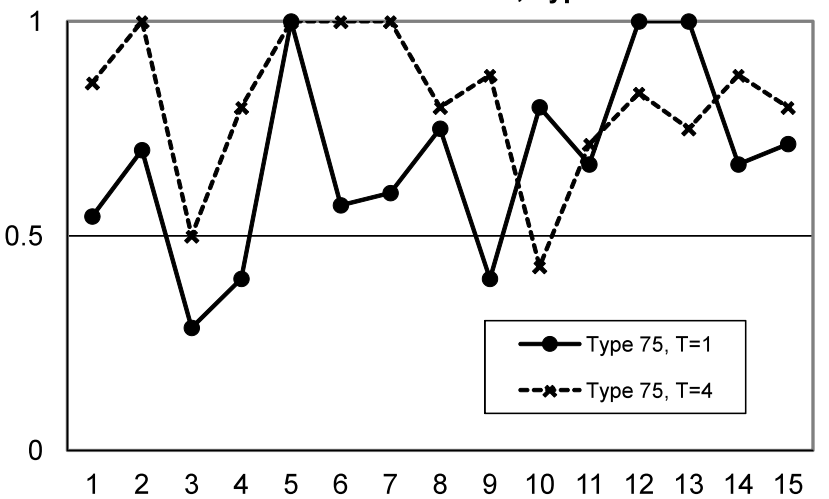


Figure 4 (cont.): Time Series by Property Rights
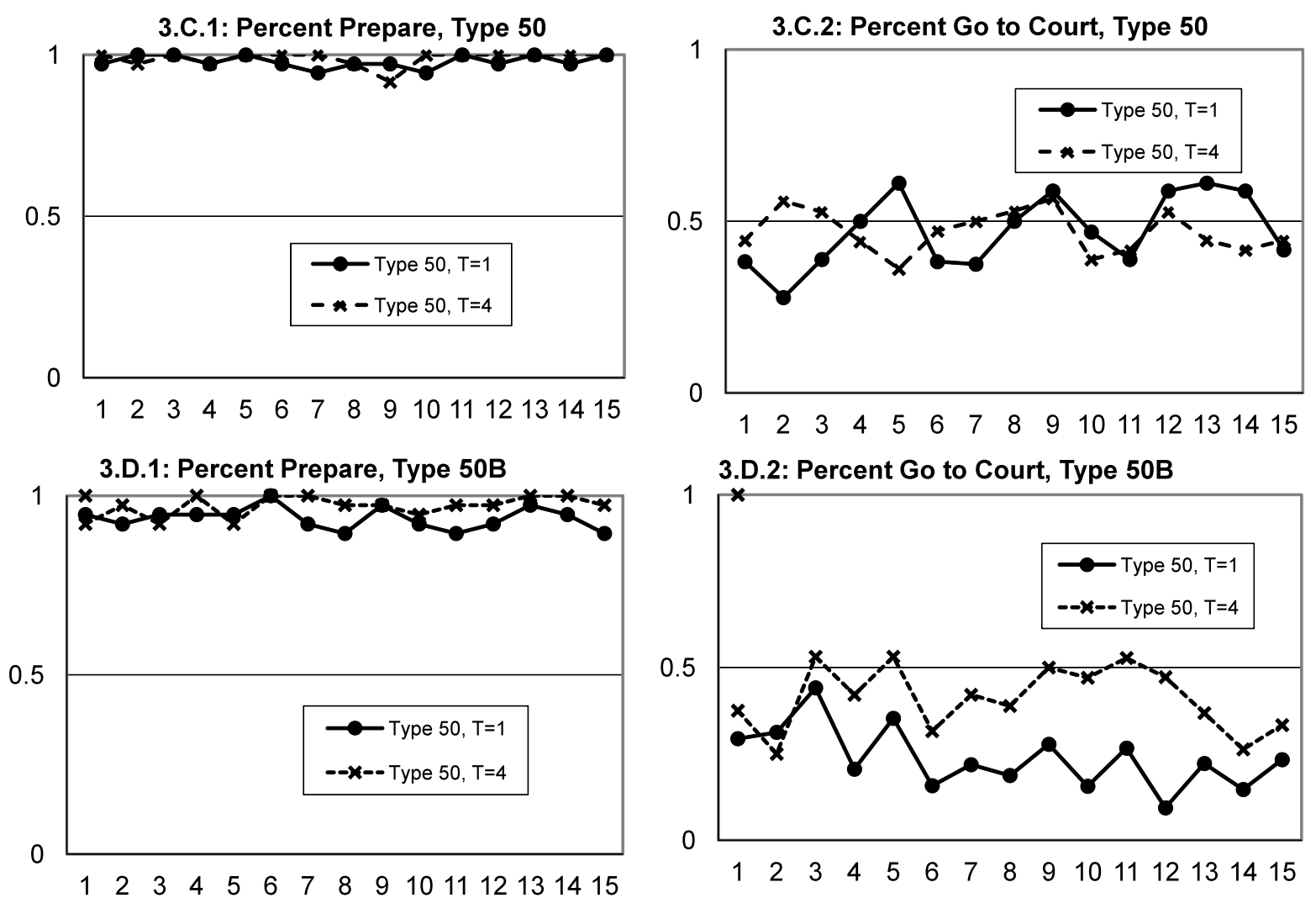
Figure 5: Average Rates of Trial, by Session and Horizon
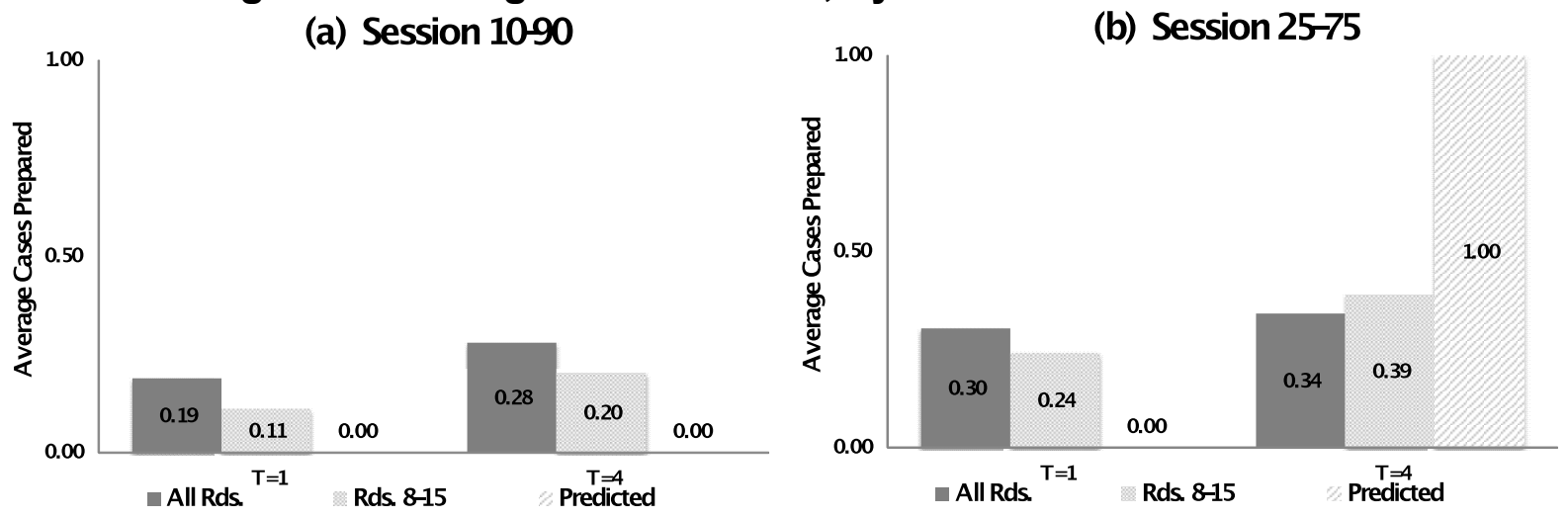

(c) Session $50-50$
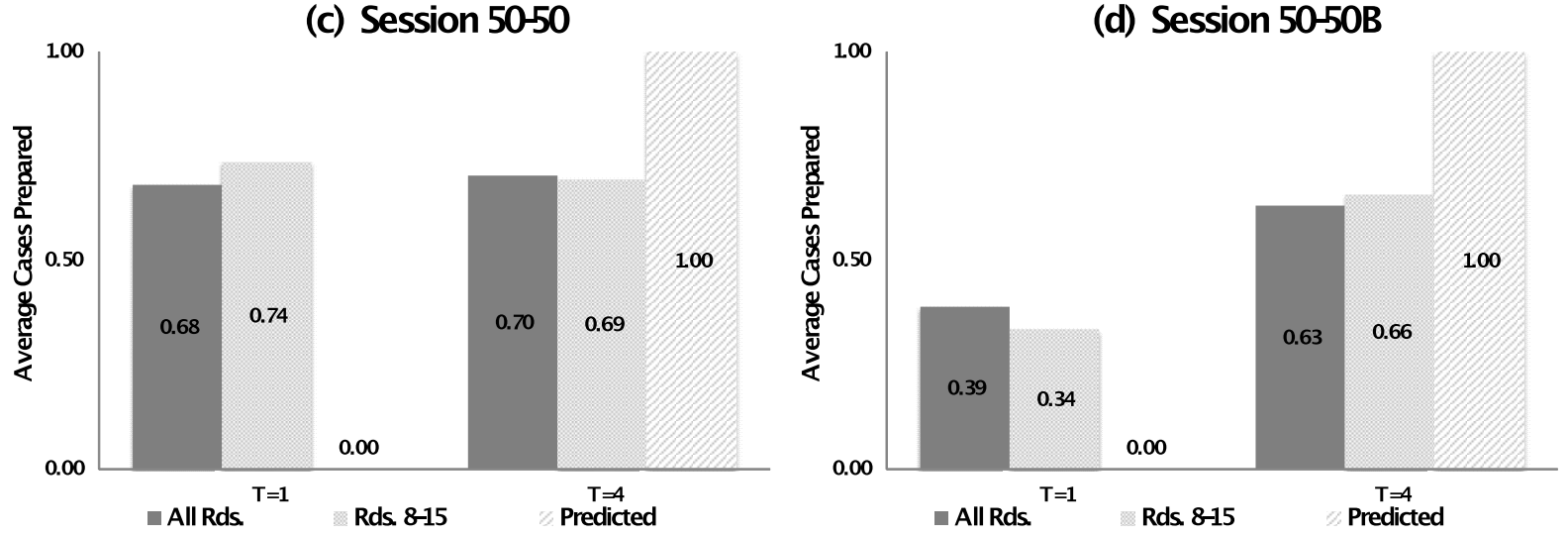
Table 5: Incidence of Trial Regression Estimates, by Session (Rounds 8-15) A: Unconditional

\begin{tabular}{|c|c|c|c|c|}
\hline Session & $10-90$ & $25-75$ & $50-50$ & $50-50 \mathrm{~B}$ \\
\hline & & & & \\
Constant & $0.11^{* * *}$ & $0.24^{* * *}$ & $0.74^{* * *}$ & $0.34^{* * *}$ \\
& $(0.03)$ & $(0.04)$ & $(0.04)$ & $(0.04)$ \\
& & & & \\
Dummy Long & $0.09^{* *}$ & $0.15^{* *}$ & -0.04 & $0.32^{* * *}$ \\
Horizon & $(0.04)$ & $(0.06)$ & $(0.05)$ & $(0.05)$ \\
& & & & \\
\hline & 304 & 256 & 288 & 304 \\
\hline
\end{tabular}

B: Conditional

\begin{tabular}{|c|c|c|c|c|}
\hline Session & $10-90$ & $25-75$ & $50-50$ & $50-50 \mathrm{~B}$ \\
\hline & & & & \\
& $0.41^{* * *}$ & $0.84^{* * *}$ & $0.77^{* * *}$ & $0.39^{* * *}$ \\
& $(0.06)$ & $(0.05)$ & $(0.04)$ & $(0.04)$ \\
& & & & \\
Dummy Long & $0.55^{* * *}$ & 0.09 & -0.05 & $0.30^{* * *}$ \\
Horizon & $(0.09)$ & $(0.07)$ & $(0.05)$ & $(0.06)$ \\
& & & & \\
\hline & 304 & 256 & 288 & 304 \\
\hline
\end{tabular}

Notes. Standard emrors in parenthses. *, **, and *** denote significance at the $10 \%$ $5 \%$, and $1 \%$ levels, respectively. 
Table 6: Proportion of Subjects with Observed Strategy in Rds. 8-15, by Session and Subject Type

\begin{tabular}{|c|c|c|c|c|c|c|c|c|c|}
\hline \multirow{2}{*}{ Session } & \multirow{2}{*}{$\begin{array}{c}\text { Subject } \\
\text { Type }\end{array}$} & \multicolumn{4}{|c|}{$T=1$} & \multicolumn{4}{|c|}{$\mathrm{T}=4$} \\
\hline & & $P$ & $\mathrm{P}, \mathrm{C}$ & $\mathrm{P}, \mathrm{NC}$ & NP & $\bar{P}$ & $P, C$ & $\mathrm{P}, \mathrm{NC}$ & NP \\
\hline \multirow{2}{*}{$10-90$} & 10 & 0.02 & 0.07 & 0.20 & 0.71 & 0.00 & 0.18 & 0.03 & 0.79 \\
\hline & 90 & 0.69 & 0.05 & 0.22 & 0.04 & 0.79 & 0.15 & 0.06 & 0.00 \\
\hline \multirow{2}{*}{$25-75$} & 25 & 0.01 & 0.14 & 0.15 & 0.70 & 0.00 & 0.27 & 0.16 & 0.58 \\
\hline & 75 & 0.70 & 0.21 & 0.08 & 0.02 & 0.58 & 0.32 & 0.10 & 0.00 \\
\hline $50-50$ & 50 & 0.02 & 0.50 & 0.46 & 0.02 & 0.01 & 0.45 & 0.52 & 0.01 \\
\hline 50-50B & 50 & 0.07 & 0.17 & 0.69 & 0.07 & 0.02 & 0.39 & 0.56 & 0.02 \\
\hline
\end{tabular}

Notes: Single lines box the choice that should be observed when both litigants play the predicted strategy. Double lines box the choice that would be observed if the subject plays the predicted strategy but the other litigant does not. 